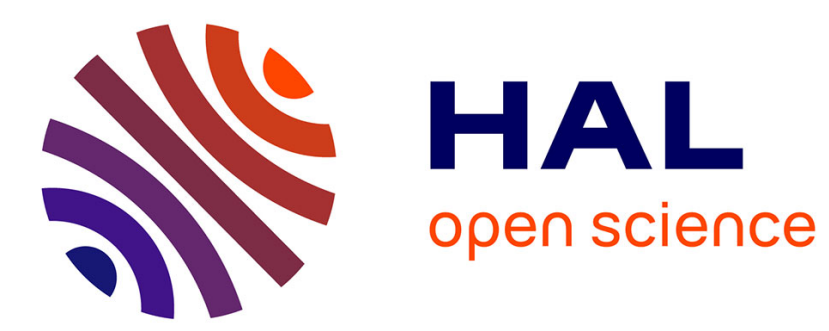

\title{
Asymmetric transformations involving 1,2-diarbonyl compounds as pronucleophiles
}

Wilfried Raimondi, Damien Bonne, Jean Rodriguez

\section{To cite this version:}

Wilfried Raimondi, Damien Bonne, Jean Rodriguez. Asymmetric transformations involving 1,2diarbonyl compounds as pronucleophiles. Chemical Communications, 2012, 48, pp.6763-6775. 10.1039/C2CC30691C . hal-00736692

\section{HAL Id: hal-00736692 https://hal.science/hal-00736692}

Submitted on 28 Sep 2013

HAL is a multi-disciplinary open access archive for the deposit and dissemination of scientific research documents, whether they are published or not. The documents may come from teaching and research institutions in France or abroad, or from public or private research centers.
L'archive ouverte pluridisciplinaire HAL, est destinée au dépôt et à la diffusion de documents scientifiques de niveau recherche, publiés ou non, émanant des établissements d'enseignement et de recherche français ou étrangers, des laboratoires publics ou privés. 


\section{Asymmetric transformations involving 1,2-dicarbonyl compounds as pronucleophiles}

\author{
Wilfried Raimondi, Damien Bonne* and Jean Rodriguez* \\ Received 31st January 2012, Accepted 24th April 2012 \\ DOI: $10.1039 / \mathrm{c} 2 \mathrm{cc} 30691 \mathrm{c}$
}

This article concentrates on the versatile nucleophilic reactivity of 1,2-dicarbonyl compounds in various asymmetric transformations. Although underexploited in comparison to their 1,3-dicarbonyl homologues, the presence of adjacent multiple reactive centres allows the selection of specific activation modes for enhancing the reactivity of these important ambident pronucleophiles. They can be involved in selective formation of $\mathrm{C}-\mathrm{C}, \mathrm{C}-\mathrm{O}$ or $\mathrm{C}-\mathrm{N}$ bonds leading to various optically active targets in the acyclic and cyclic series including three- to seven-membered ring systems. Recent contributions in the field of biochemical, organometallic and organic catalytic transformations as well as some relevant stoichiometric approaches are discussed from synthetic and mechanistic point of views highlighting some important stereochemical issues.

\section{Introduction}

Pyruvic acid, one of the simplest 1,2-dicarbonyl compounds, has been used as a nucleophile for thousand years by Nature ${ }^{1}$ itself in the biosynthesis of sialic and ulosonic acids which are nine-carbon polyhydroxylated $\alpha$-keto acids found in vertebrate glycoconjugates. ${ }^{2}$ In parallel, the first synthesis of an $\alpha$-keto acid was accomplished by Berzelius in $1835 .^{3}$

Aix-Marseille Université, UMR CNRS 7313 iSm2,

Centre Saint Jérôme, service 531, 13397 Marseille, France.

E-mail: jean.rodriguez@univ-amu.fr,damien.bonne@univ-amu.fr;

Fax: + 33491289 187; Tel: +33491289187
Recently, 1,2-keto acids were shown to be particularly useful as they reacted efficiently with hydroxylamine derivatives for chemoselective amide ligations. ${ }^{4}$ The apparently simple use of a 1,2-dicarbonyl compound as a $\mathrm{d}^{2}$ synthon (Fig. 1) ${ }^{5}$ remained unknown until the pioneer non-direct use of $\alpha$-keto esters as their chiral hydrazones by Enders in the nineties (vide infra).

Until now, utilisation of 1,2-dicarbonyls in asymmetric transformations was mostly limited to the increased electrophilic ketone reactivity by the presence of an adjacent carbonyl group. In fact, 1,2-dicarbonyl compounds are sometimes used allowing the extension of reaction scope that was limited to aldehydes. ${ }^{6}$ Nowadays, the elaboration of new methodologies

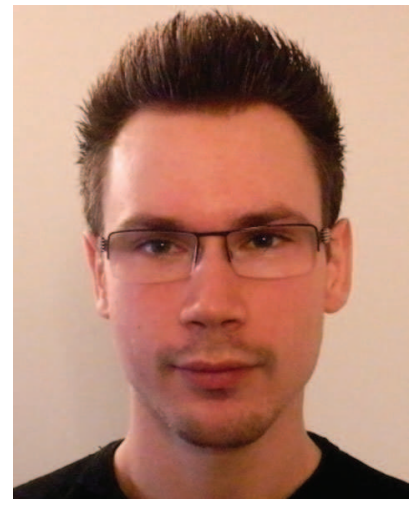

Wilfried Raimondi
Wilfried Raimondi was born in Orsay (France) in June 1986. In 2006, he joined the Ecole Nationale Supérieure de Chimie de Clermont Ferrand (ENSCCF) where he was awarded both his MSc and $B S c$ in chemistry. He is now pursuing his PhD under the supervision of Prof. Jean Rodriguez and Dr Damien Bonne at Aix-Marseille Université. His research focuses on the development of new organocatalysed methodologies and their application in total synthesis.

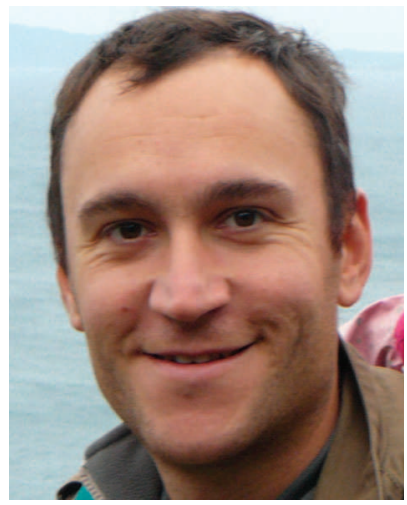

Damien Bonne
Damien Bonne was born in Epinal (France) in 1979. After studying chemistry at the Ecole Supérieure de Chimie de Lyon (CPE Lyon, France), he completed his $P h D$ in 2006 under the supervision of Prof. Jieping Zhu working on isocyanide-based multicomponent reactions. He then moved to the University of Bristol (UK) to join the group of Prof. Varinder A. Aggarwal as a post-doctoral associate. Since 2007 he has been working as an assistant professor with Prof. Jean Rodriguez at Aix-Marseille Université (France). His research interests include the development of new asymmetric organocatalysed methodologies and their application in stereoselective synthesis. 


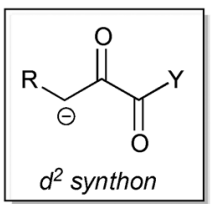

Fig. 1 1,2-Dicarbonyl $d^{2}$ synthon.

involving 1,2-dicarbonyl compounds as efficient pronucleophiles is increasing rapidly for mainly two reasons:

- First, these reactive species became very popular and particularly attractive synthetic scaffolds thanks to their dense number of reactive centres coupled with their ambident reactivity that can be exploited in sequential reactions or in cascade transformations to form hetero- or carbocycles.

- A second reason could be the important progress that has been done in the development of new suitable selective activation modes for enhancing the nucleophilic potential of 1,2-dicarbonyls towards cross-condensation instead of their competitive reactivity as electrophiles leading to useless selfcondensation.

In this feature article, we will try to demonstrate that acyclic and cyclic 1,2-dicarbonyls possess exceptionally useful synthetic features and how they have been exploited as nucleophiles using either bio-, metal- or organo-catalysts together with some important stoichiometric transformations (Scheme 1).

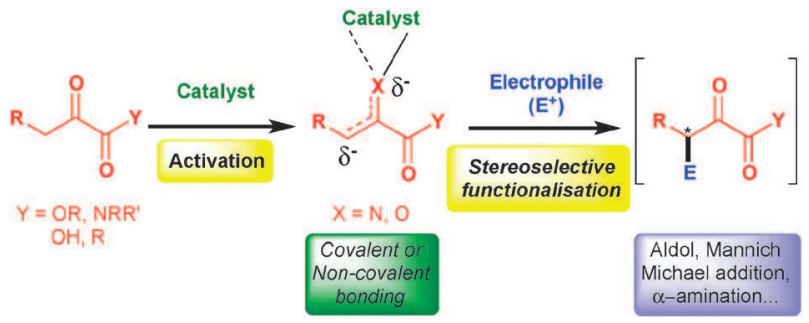

Scheme 1 Nucleophilic potential of 1,2-dicarbonyls.

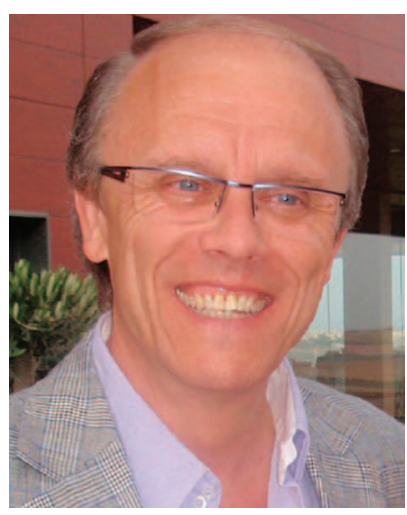

Jean Rodriguez was born in Cieza (Spain) in 1958 and in 1959 his family emigrated to France. After studying chemistry at Aix-Marseille Université (France), he completed his PhD as a CNRS researcher with Prof. Bernard Waegell and Prof. Pierre Brun in 1987. He completed his Habilitation in 1992, also at Marseille, where he is currently the Professor and Director of the UMR-CNRS7313-iSm2. His research interests include the development of domino and multicomponent reactions, and their application in stereoselective synthesis. In 1998 he was awarded the ACROS prize in Organic Chemistry, and in 2009 he was awarded the prize of the Division of Organic Chemistry from the French Chemical Society.

\section{Biochemical transformations}

In biosynthesis, pyruvic acid is used as a key $\mathrm{C} 2$ and $\mathrm{C} 3$ donor unit. For example, its direct irreversible carboxylation to oxaloacetic acid (Wood-Werkman reaction) ${ }^{7}$ by pyruvate carboxylases is a key step in the essential Krebs citric acid cycle. ${ }^{8}$ Alternatively, the pyruvate- and phosphenolpyruvatedependent aldolases are a specific group of enzymes that catalyse the stereoselective addition of pyruvic acid to various aldehyde acceptors. ${ }^{9}$ In bacterial systems, sialic acids are biosynthesised by the enzyme $N$-acetylneuraminic acid (NeuAc) aldolase (Scheme 2). The enzyme uses a mannose derivative $\mathbf{1}$ as a substrate, inserting three carbons from pyruvate 2 into the resulting sialic acid structure $3{ }^{10}$ The enzyme is a type I aldolase and forms an enamine with a lysine residue and the pyruvate which then reacts with the $N$-acetyl-D-mannosamine in a reversible manner. The imidazole group of a histidine residue is presumed to protonate and activate the aldehyde group of the acceptor substrate.

Many studies regarding biocatalysed aldol reactions with pyruvate as the donor have been carried out using the commercially available NeuAc aldolase because of its high specificity for pyruvate as a donor substrate and its high tolerance for a variety of acceptors. ${ }^{11}$ These biocatalysed aldol reactions can be performed in aqueous solution at neutral $\mathrm{pH}$ and can be achieved without extensive protection methodology. NeuAc aldolase displays a broad tolerance for aldehyde acceptors, including pentoses, hexoses, aminosugars, monoand disaccharides. ${ }^{12}$

Unlike most aldolases, NeuAc aldolase appears to induce unusual stereoselectivity, ${ }^{13}$ and therefore, the stereochemical outcome of the catalysed reactions depends on the structure of the acceptor aldehyde (Scheme 3). ${ }^{14}$ In acceptors with the $(S)$ configuration at $\mathrm{C} 3$ such as $\mathbf{4}$, the carbonyl group reacts from the $S i$ face to form a new stereogenic centre with $(S)$ configuration and an axial orientation in the final product $\mathbf{5}$. These reactions are presumably under kinetic control. On the other hand, substrates such as $\mathbf{6}$ with the opposite configuration at C3 suffer a nucleophilic addition of the pyruvate from the $R e$ face, giving the $(R)$ configuration in product 7 . In these cases,

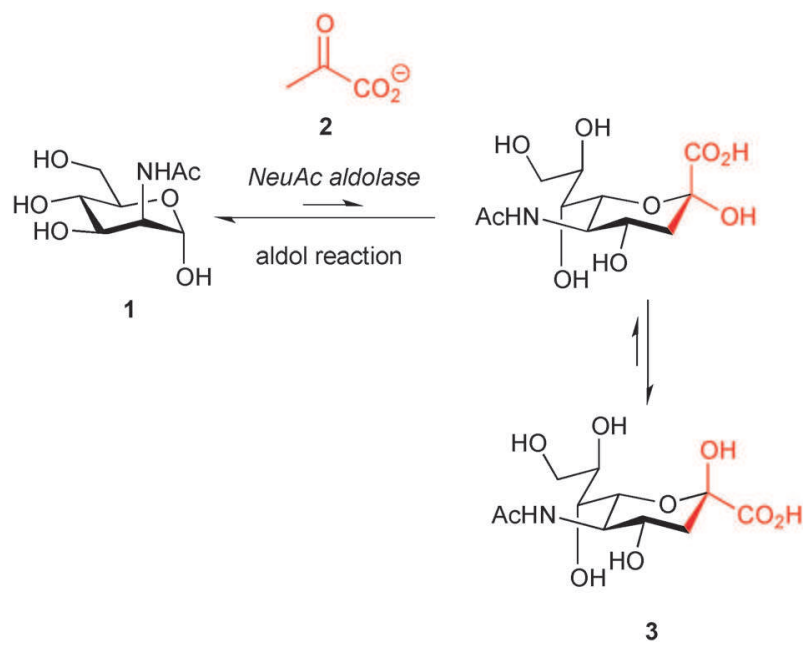

Scheme 2 Aldol condensation mediated in vivo by NeuAc aldolase. 


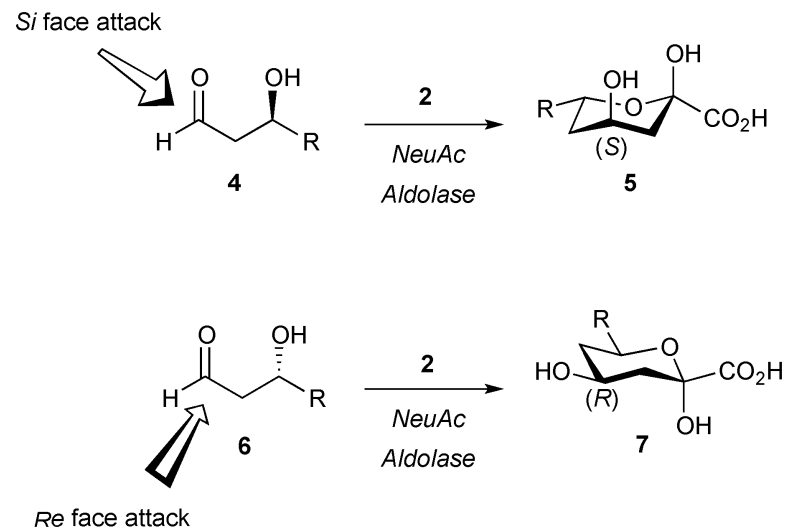

Scheme 3 NeuAc aldolase-catalysed aldol reaction: stereochemical outcome.
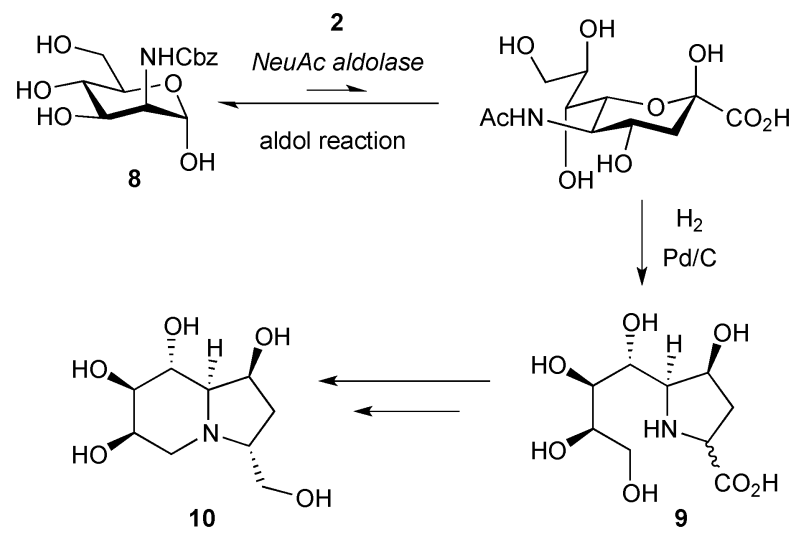

Scheme 4 NeuAc aldolase preparation of azasugars.

the formation of the $(R)$ products is under thermodynamic control since the newly formed stereocentre is in the equatorial position.

Azasugars have been also prepared with NeuAc aldolase (Scheme 4). ${ }^{15}$ The biocatalysed addition of pyruvate 2 to mannosamine derivative $\mathbf{8}$ is followed by reductive amination to give the pyrrolidines $\mathbf{9}$, which was further converted into 3-(hydroxymethyl)-6-epicastanospermine $\mathbf{1 0}$.

Other pyruvate- and phosphoenolpyruvate-dependent aldolases have been isolated, purified and exploited in synthesis. For example, 2-keto-3-deoxy-6-phospholuconate (KDPG) aldolase was shown to efficiently catalyse the aldol reaction between 2-pyridine carboxaldehyde $\mathbf{1 1}$ and pyruvate $\mathbf{2}$ with an extremely high level of enantioselectivity (Scheme 5). ${ }^{16}$

Although of particular relevant importance in Nature the specificity of the enzymatic systems involved for the selective functionalisation of pyruvic acid has encountered only limited application in synthetic organic chemistry. However, the high synthetic potential of such a simple condensation has raised a

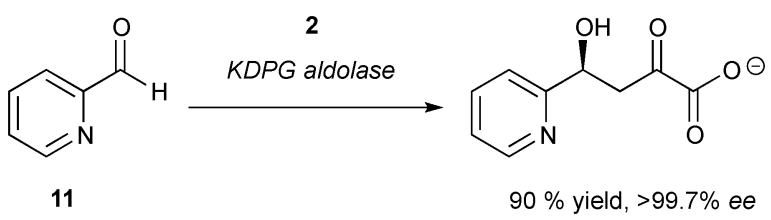

Scheme 5 KDPG aldolase-catalysed enantioselective aldol reaction. huge interest and more general biomimetic metallo- or organocatalysed approaches have emerged during the last decade.

\section{Metallocatalysed transformations}

The first example of the direct use of a 1,2-dicarbonyl compound as a pronucleophile in a stereoselective chemical transformation was reported by Jørgensen who showed that chiral Lewis acids could efficiently catalyse the homo-aldol reaction of ethyl pyruvate (12). ${ }^{17}$ They used a chiral copper(II)-bisoxazoline complex 13 providing diethyl-2-hydroxy-2-methyl-4-oxoglutarate (14) in a promising $80 \%$ yield and $96 \%$ ee (Scheme 6). In fact, this transformation was at the time of its discovery very significant since it mimics the pyruvate- and phosphenolpyruvatedependent aldolases. ${ }^{9}$ The chiral Lewis catalyst promotes both the formation and the stabilisation of the enol-pyruvate and controls the stereochemistry of the reaction.

Short after, the same group proposed a related coppercatalysed diastereo- and enantioselective Mannich reaction of $\alpha$-keto esters 15 with an $N$-tosyl- $\alpha$-imino ester $\mathbf{1 6}$ (Scheme 7). ${ }^{18}$ This methodology gives simple access to $\alpha$-amino acid derivatives 17 that are precursors of highly functionalised optically pure lactones 18 by selective reduction of the 4-oxo moiety.

However this seminal transformation was limited to $N$-toluenesulfonyl glyoxylic imines and this drawback was addressed only several years later by Shibasaki and co-workers. ${ }^{19}$ They developed a direct asymmetric Mannich reaction of 1,2keto anilides 19 with various $N$-thiophenesulfonyl imines 20a. A heterobimetallic lanthanum aryloxide/lithium aryloxide/pybox

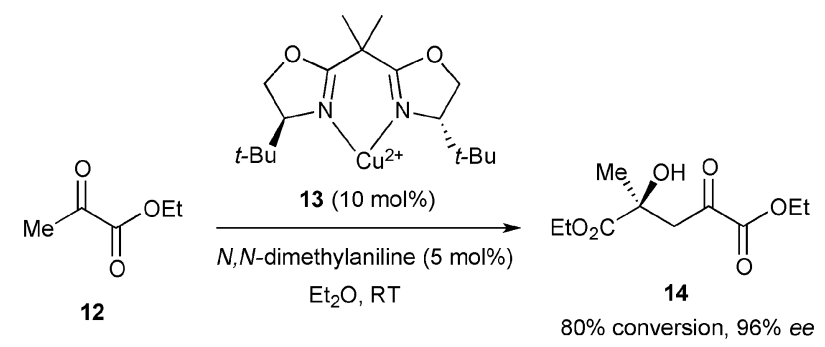

Scheme 6 Chiral Lewis acid catalysed homo-aldol reaction.

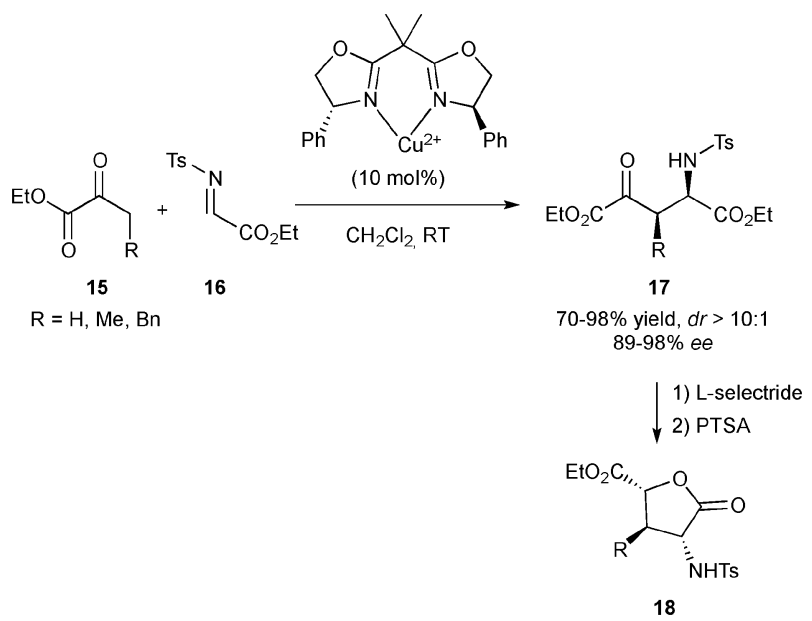

Scheme 7 Asymmetric direct Mannich reaction of 1,2-keto esters with $\alpha$-imino esters. 


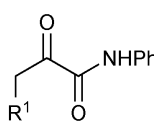

19

$\mathrm{R}^{1}=\mathrm{Me}, \mathrm{Et}, \mathrm{Bn}$

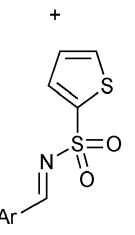

20a
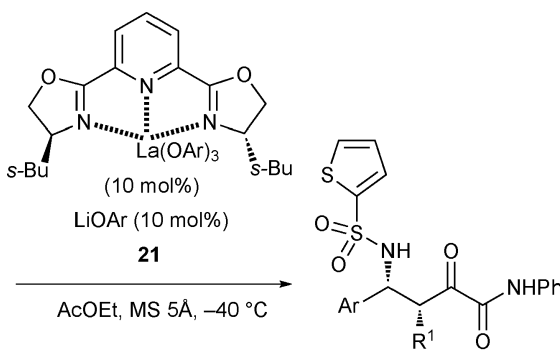

22

$74-99 \%$ yield, $d r 77: 23$ to $97: 3$ $83-90 \%$ ee $\mathrm{KBH}_{4}$ $\mathrm{MeOH},-40^{\circ} \mathrm{C}$ $2.5 \mathrm{~h}$

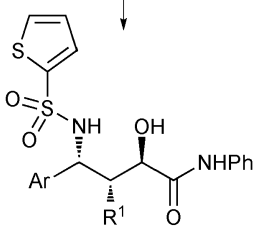

23

$>99 \%$ yield, $d r 17: 1$

Scheme 8 Direct $s y n$-selective asymmetric Mannich reaction of $\alpha$-keto anilides.

complex 21 promoted the syn-Mannich-type reaction, affording $\gamma$-amino amides 22 in good yields and selectivity (Scheme 8). Still, the use of aliphatic $N$-thiophenesulfonyl imines afforded the product in lower yield and selectivity. Highly diastereoselective reduction of the ketone moiety of $\mathbf{2 2}$ using $\mathrm{KBH}_{4}$ gave the $\beta$-alkyl- $\gamma$-amino- $\alpha$-hydroxy amides 23 with three contiguous stereogenic centres with an anti/syn relationship.

One year after this important report, the same team described the complementary anti-selective direct catalytic enantioselective Mannich-type reaction of $\alpha$-keto anilide donors 19 with $N$-o-nitrophenyl sulfonyl imine 20b (Scheme 9). ${ }^{20}$ The homodinuclear nickel complex $\mathbf{2 4}$ promoted the reaction to afford the product $\mathbf{2 5}$ in up to $99 \%$ yield with an anti/syn ratio of more than 50:1 and up to $95 \%$ ee. The products of the reaction could be stereoselectively reduced with K-Selectride ${ }^{\mathbb{R}}$ to give the $\alpha$-hydroxy $\beta$-alkyl $\gamma$-amino amides 26 with three stereogenic centres with an anti/anti relative configuration. These products could also be easily converted to the optically active azetidine-2-amides 27 with a syn/anti configuration.

The first example of a diastereo- and enantioselective conjugate addition of 1,2-keto esters to nitroalkenes was reported by Sodeoka and co-workers in $2010 .^{21,22}$ They used a mononuclear nickel complex with a chiral 1,2-trans-cyclohexane diamine ligand and the anti-Michael adducts $\mathbf{2 8}$ were isolated in good to excellent yield and selectivities (Scheme 10). One of the main advantages of the method over the previous use of 1,2-dicarbonyl as nucleophiles in metal catalysed stereoselective transformations is the relatively low catalyst loading required $(1 \mathrm{~mol} \%)$. The synthetic usefulness of this methodology was proven by its application to the synthesis of the kainic acid analogue 29 in only eight steps from the Michael adduct 28a in a promising $42 \%$ overall yield.

Michael adducts $\mathbf{2 8}$ can further react in successive domino reaction as shown very recently by Huang and co-workers who<smiles>O=[N+]([O-])c1ccccc1S(=O)(=O)/N=C/Br</smiles>

20b<smiles>[R]CC(=O)C(=O)Nc1ccccc1</smiles>

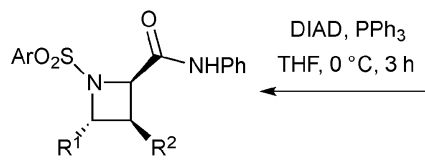

27

$67-80 \%$ yield

$24(10 \mathrm{~mol} \%)$

$\mathrm{THF}, 0^{\circ} \mathrm{C}$

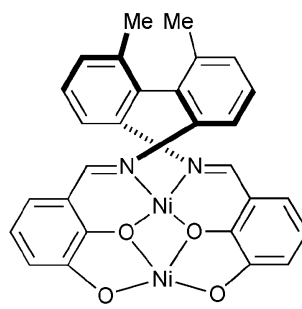<smiles>[R]C(C(=O)C(=O)Nc1ccccc1)[C@@H]([R7])NS(=O)(=O)c1ccccc1[N+](=O)[O-]</smiles>

25

$76-99 \%$ yield, $d r 15: 1$ to $>50: 1$ $91-95 \%$ ee

K-selectride ${ }^{\circledR}$ $\mathrm{THF},-78^{\circ} \mathrm{C}$ $2 \mathrm{~h}$

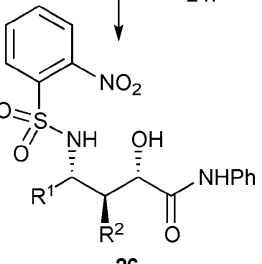

$80-90 \%$ yield, $d r>30: 1$
Scheme 9 Direct anti-selective asymmetric Mannich reaction of $\alpha$-keto anilides.

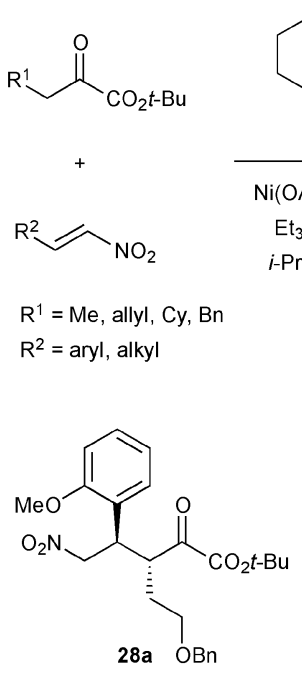

$93 \%$ yield, $d r>30: 1,91 \%$ ee

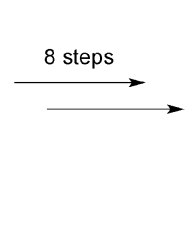
$42 \%$ overall yield
Scheme 10 Asymmetric Michael addition of 1,2-keto esters to nitroalkenes with mononuclear $\mathrm{Ni}$ catalyst.

showed that 1,2-keto esters could efficiently participate in an elegant asymmetric Michael-Michael-Henry sequence with nitroalkenes as electrophiles catalysed by a new copper(II) complex incorporating a rigid chiral diamine (Scheme 11). ${ }^{23}$ The counter anion played an important role and the copper salt containing the acetate anion proved to be the most efficient one for achieving high reactivity and selectivities in the formation of highly functionalised cyclohexanes 30. Using triethylamine as an additive $(5 \mathrm{~mol} \%)$, the catalyst loading 


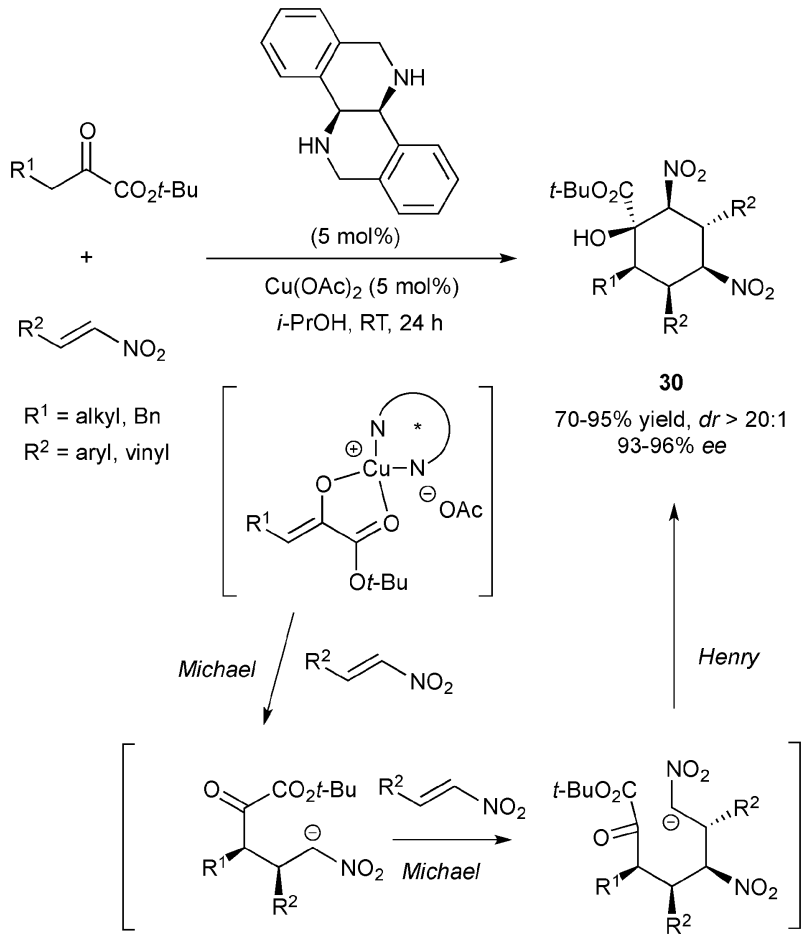

Scheme 11 Asymmetric synthesis of functionalized cyclohexanes via Michael-Michael-Henry domino sequence.

could be decreased to $0.1 \mathrm{~mol} \%$. This sequence was previously described using bifunctional organocatalysis and 1,2-keto amides as starting materials (vide infra).

Shibasaki's group employed the previously developed dinuclear nickel complex $\mathbf{2 4}$ to catalyse a complementary syn-selective asymmetric 1,4 -addition of $\alpha$-keto anilides 19 to nitroalkenes. ${ }^{24}$ The products 31 were obtained in good to excellent yields with also good selectivities (Scheme 12). As seen previously, the Michael adducts 31 could easily be converted to the corresponding tri-substituted pyrrolidines 32 with a syn/anti relationship, which nicely complements the report of Sodeoka (Scheme 10).
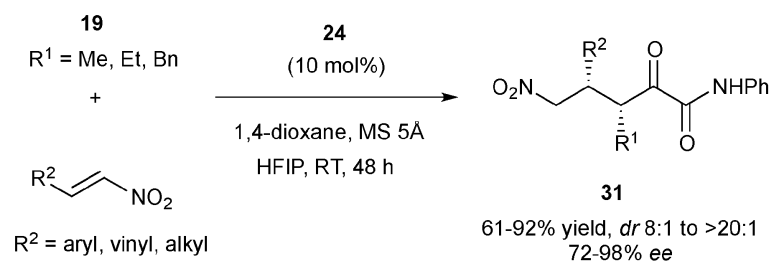

Raney $\mathrm{Ni}, \mathrm{H}_{2}$ $\mathrm{EtOH}, 65^{\circ} \mathrm{C}$ $14 \mathrm{~h}$

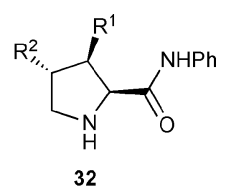

$\mathrm{R}^{2}=4-\mathrm{MeO}-\mathrm{Ph}, \mathrm{R}^{1}=\mathrm{Me}, 71 \%$ yield

Scheme 12 Asymmetric Michael addition of 1,2-keto esters to nitroalkenes with binuclear Ni catalyst.

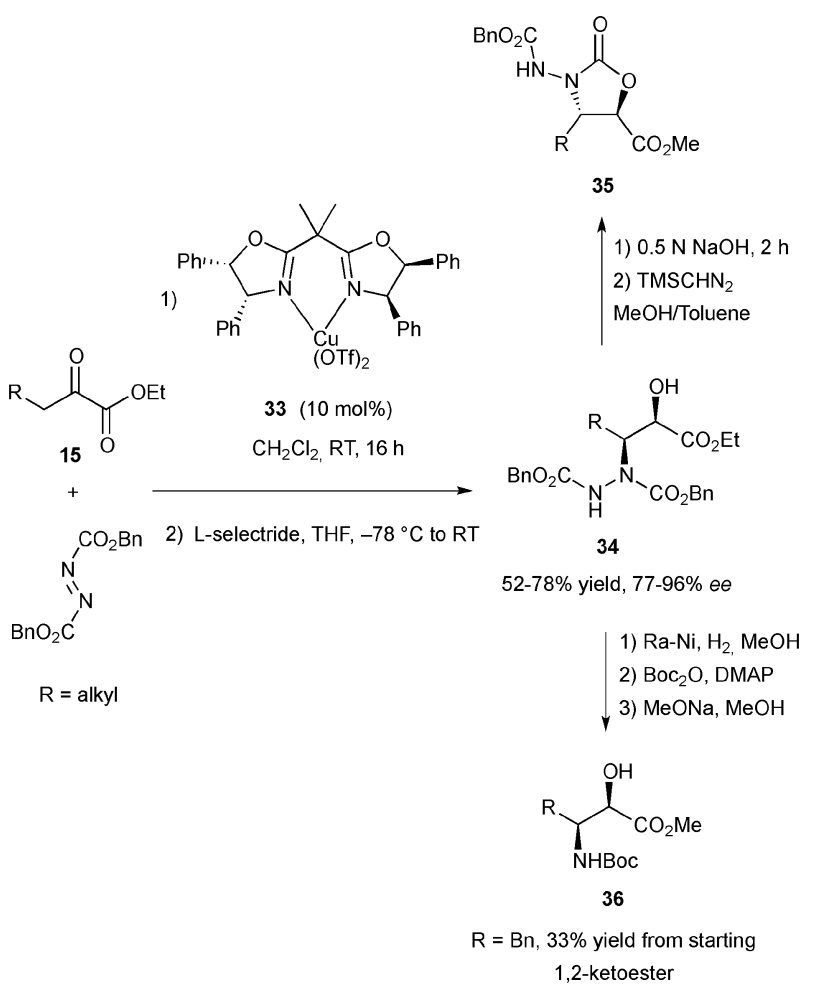

Scheme 13 Chiral bisoxazoline-copper(II) complex catalysed enantioselective $\alpha$-amination of 1,2 -keto esters.

Besides $\mathrm{C}-\mathrm{C}$ bond formations, 1,2-dicarbonyls have also been successfully activated to form $\mathrm{C}-\mathrm{N}$ bonds in a stereoselective manner. An early report by Jørgensen and co-workers, who are undoubtedly pioneers in this field, deals with the enantioselective direct $\alpha$-amination of 1,2-keto esters $\mathbf{1 5}$ catalysed by a chiral bisoxazoline-copper(II) complex 33 (Scheme 13). ${ }^{25}$ Products were formed smoothly but their purification (flash chromatography) partially erodes the enantioselectivity. In consequence, reaction products were first reduced with L-Selectride ${ }^{\mathbb{R}}$ to the hydroxy esters 34 and cyclised to the $\mathrm{N}$-amino oxazolidinone 35 . An important application of this reaction is the facile access to the corresponding syn- $\beta$-amino- $\alpha$-hydroxy esters 36 . Hence reductive cleavage of both carboxybenzyl groups and the $\mathrm{N}-\mathrm{N}$ bond by hydrogen and Raney ${ }^{\mathbb{R}}-\mathrm{Ni}$, respectively, and subsequent protection of the amino group afforded 36 in good yield without racemisation of the stereogenic centres.

Finally, the first example of catalytic asymmetric monofluorination of $\alpha$-keto esters was described very recently by Sodeoka and co-workers using $N$-fluorobenzenesulfonimide (NFSI) as the fluoronating agent and a chiral palladium $\mu$-hydroxo complex 37 (Scheme 14). ${ }^{26}$ The desired $\beta$-fluorinated$\alpha$-keto esters 38 were obtained in good yields and excellent enantioselectivity and the ketone moiety could be reduced to the corresponding syn $\beta$-fluoro- $\alpha$-hydroxy esters with moderate diastereoselectivity. Anti $\beta$-fluoro- $\alpha$-hydroxy esters could also be obtained using enzymatic reduction $(\mathrm{dr}>30: 1)$. A chiral square-planar bidentate Pd-enolate structure 39 was invoked to explain the enantioselection of the reaction where one of the enolate faces is shielded by an equatorial aryl group of the ligand and the tert-butyl ester moiety. 

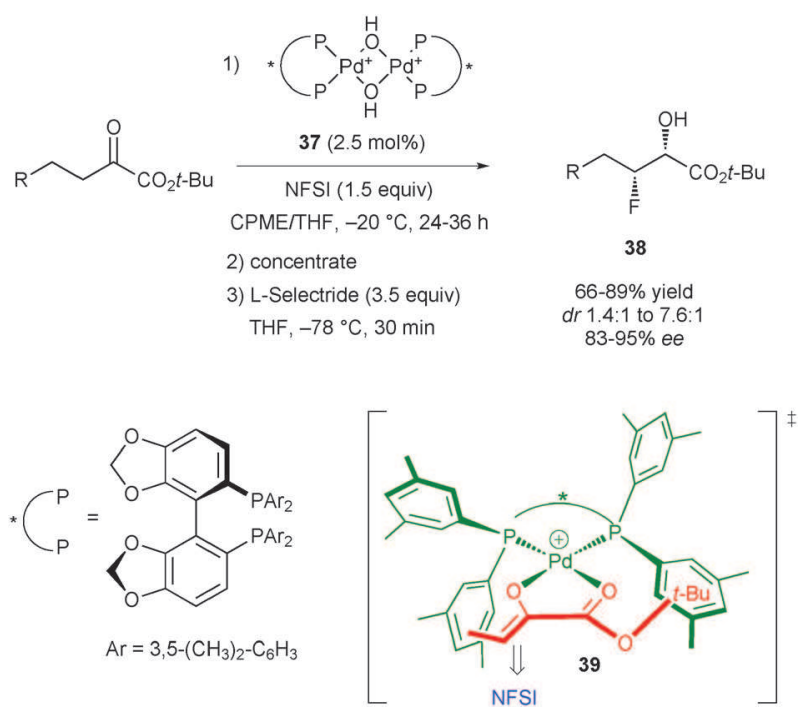

Scheme 14 Catalytic asymmetric mono-fluorination of $\alpha$-keto esters.

Clearly, organometallic catalysis offers versatile tools and provides complementary activation modes of 1,2-dicarbonyls. Efficient stereocontrol is observed in the formation of both $\mathrm{C}-\mathrm{C}$ and $\mathrm{C}-\mathrm{N}$ bonds and stereodivergent functionalisations are possible by simply changing the nature of the metal catalyst.

\section{Organocatalysed transformations ${ }^{27}$}

In 2004, Yamamoto and coworkers showed that 1,2-keto esters could be specifically activated using organic catalysts. They described one single example of an organocatalytic asymmetric cross-aldol reaction of ethyl pyruvate (12) and chloral (40) via enamine activation with a proline-tetrazole catalyst 41 assisted by water (Scheme 15). ${ }^{28}$ The catalyst presumably activates the ethyl pyruvate by formation of the corresponding enamine $\mathbf{4 2}$ while the tetrazole moiety protonates the acceptor enhancing its reactivity to give the $\beta$-aldol 43 in $55 \%$ yield and $86 \%$ ee.

Exploiting the well-known ambident reactivity of pyruvates, Dondoni et al. disclosed in 2005 an interesting enantioselective organocatalytic domino reaction initiated by a homo-aldol reaction. ${ }^{29}$ This provided for the first time an efficient access to enantiomerically enriched isotetronic acid $\mathbf{4 5}$ from ethyl pyruvate

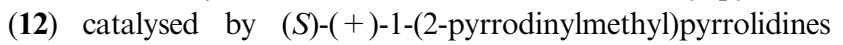
(44) in combination with TFA as co-catalyst (Scheme 16).

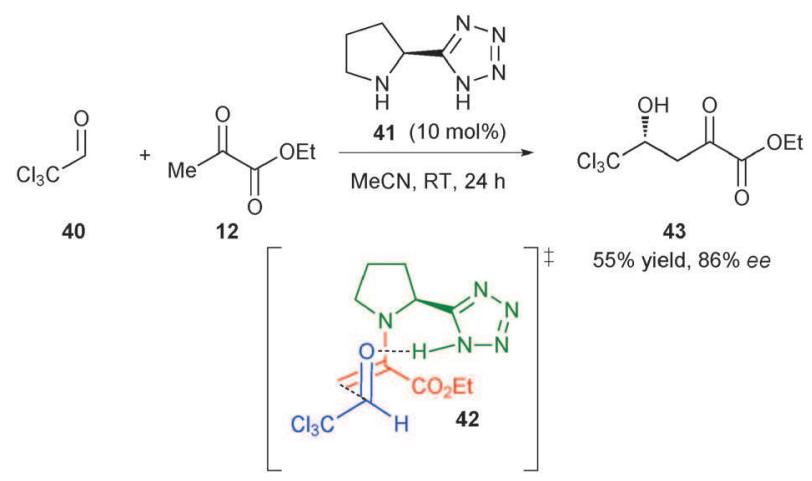

Scheme 15 Organocatalysed asymmetric cross-aldol reaction.

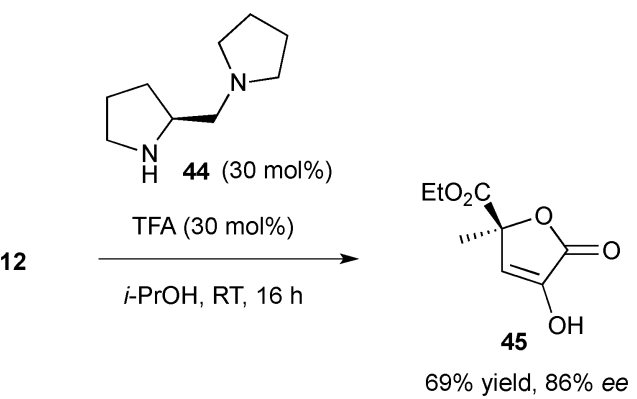

Scheme 16 Asymmetric homo-aldol reaction of ethyl pyruvate.

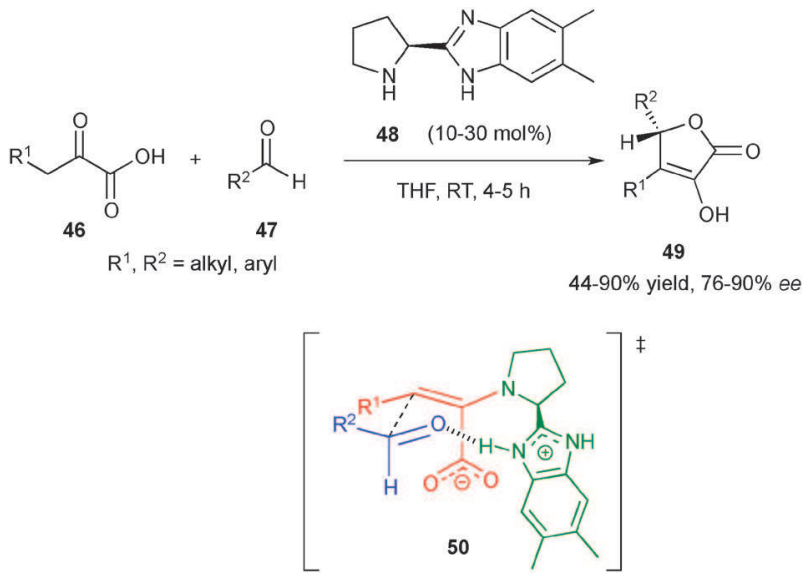

Scheme 17 Enantioselective cross-aldolisation-lactonisation sequence.

This domino process was extended three years later to a more general enantioselective cross-aldolisation-lactonisation sequence between $\alpha$-oxocarboxylic acids 46 and various aldehydes 47 with a benzimidazole proline-derived organocatalyst 48 by Landais and co-workers for the synthesis of various isotetronic derivatives 49 (Scheme 17). ${ }^{30}$ To explain the stereochemistry obtained, the authors postulated for a rigid chair-like transition state where the benzimidazole ring is protonated by the carboxylic acid and the aldehyde is activated through hydrogen-bonding with the $\mathrm{N}-\mathrm{H}$ bond of the catalyst as shown in transition state $\mathbf{5 0 .}$

In 2010, we have described the first organocatalytic enantioand diastereoselective conjugate addition of $\alpha$-keto anilides $\mathbf{1 9}$ to nitroalkenes using the bifunctional amino thiourea catalyst 51 (Scheme 18). ${ }^{31}$ In this new approach, we have demonstrated the crucial role of the amide proton in the formation of the anti-Michael adducts $\mathbf{5 3}$ in high yields and high stereoselectivities providing a nice complement to Shibasaki's $s y n$-selective organometallic activation. ${ }^{24}$ The proposed transition state involves electrophilic activation of the nitroalkene via a bidentate H-bonding interaction with both the thiourea and the amide moieties. Concomitant soft-enolisation of the 1,2-keto amide with the catalyst's tertiary amine would result in a rigid multiple $\mathrm{H}$-bonded transition state where the $S i$ face of the (Z)-enolate $\mathbf{5 2}$ would preferentially react with the $R e$ face of the nitroalkene.

The versatile reactivity of these chiral 1,2-dicarbonyls was illustrated by a pseudo three-component domino MichaelMichael-Henry reaction with simple keto amide $\mathbf{1 9}\left(\mathrm{R}^{1}=\mathrm{Me}\right)$ 


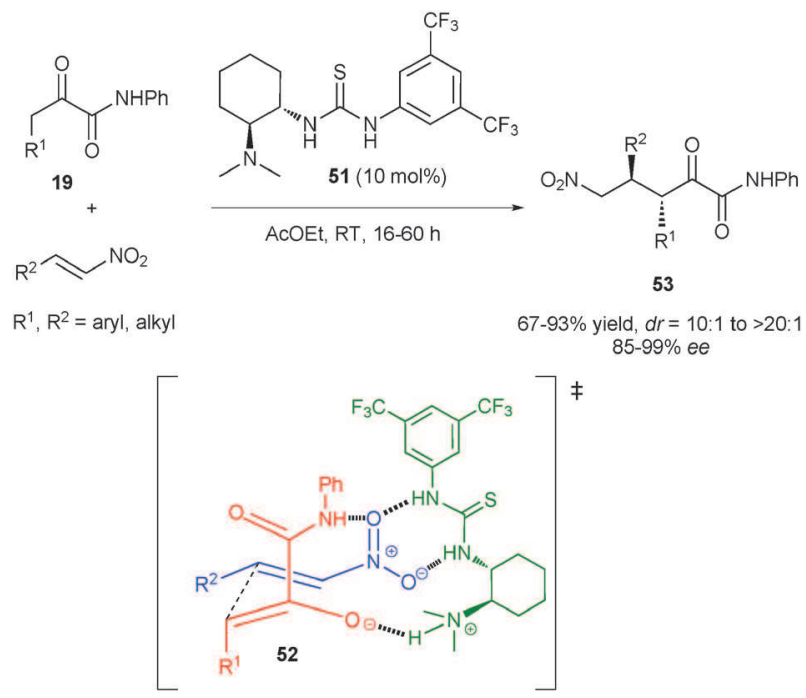

Scheme 18 Enantioselective conjugate addition with $\alpha$-keto anilides.

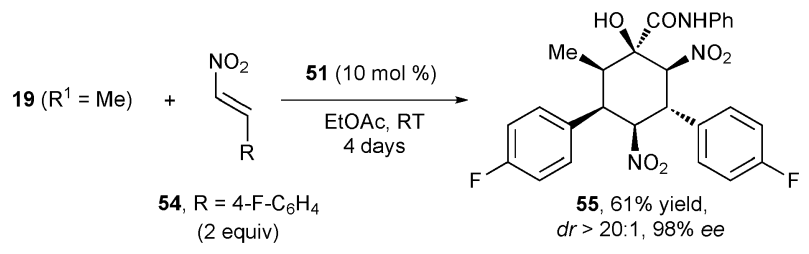

Scheme 19 Diastereo- and enantioselective domino cyclisation.

and 4-fluoro-nitrostyrene $\mathbf{5 4}$ affording the hexasubstituted cyclohexane 55 with the creation and control of six stereogenic centres in one synthetic operation (Scheme 19). ${ }^{31}$ In this cascade reaction both nucleophilic and electrophilic characters of the 1,2-keto amide are exploited.

More recently, the Michael addition was extrapolated to 1,2-keto esters 56 giving $\alpha$-functionalised chiral anti-Michael adducts 57, which were easily converted to five-membered heterocycles $\mathbf{5 8}$ or carbocycles $\mathbf{5 9}$ with additional controlled stereocentres (Scheme 20). ${ }^{32}$

Pápai's model was invoked to explain the stereochemical outcome of these reactions involving 1,2-keto esters as pronucleophiles (this explains also the stereochemistry of the enantioselective conjugate addition with 1,2-keto amides). ${ }^{33}$ The protonated tertiary amine of catalyst $\mathbf{5 1}$ binds to the nitro function, hence enhancing the electrophilic character of the nitroalkene, whereas the thiourea moiety binds to the strongly polarised enolate (Scheme 21). In the resulting conformationally restrained environment, the $S i$ face of the thermodynamic (Z)-enolate preferentially attacks the $R e$ face of the nitroalkene accounting for the formation of the anti- $(R, R)$-Michael adduct. The formation of the $s y n$-Michael adduct, which would come from the $R e$ face attack of the $(Z)$-enolate, is minor (syn : anti< $1: 20)$. In this transition state, the binding of the thiourea moiety to the enolate is disfavored because of the strong steric interaction between the benzylic ester function and the catalyst.

Besides 1,2-keto acid derivatives, highly reactive 1,2-diketones are also particularly attractive species for the development of domino reactions by combining both their nucleophilic and electrophilic characters in successive transformations. However, this was

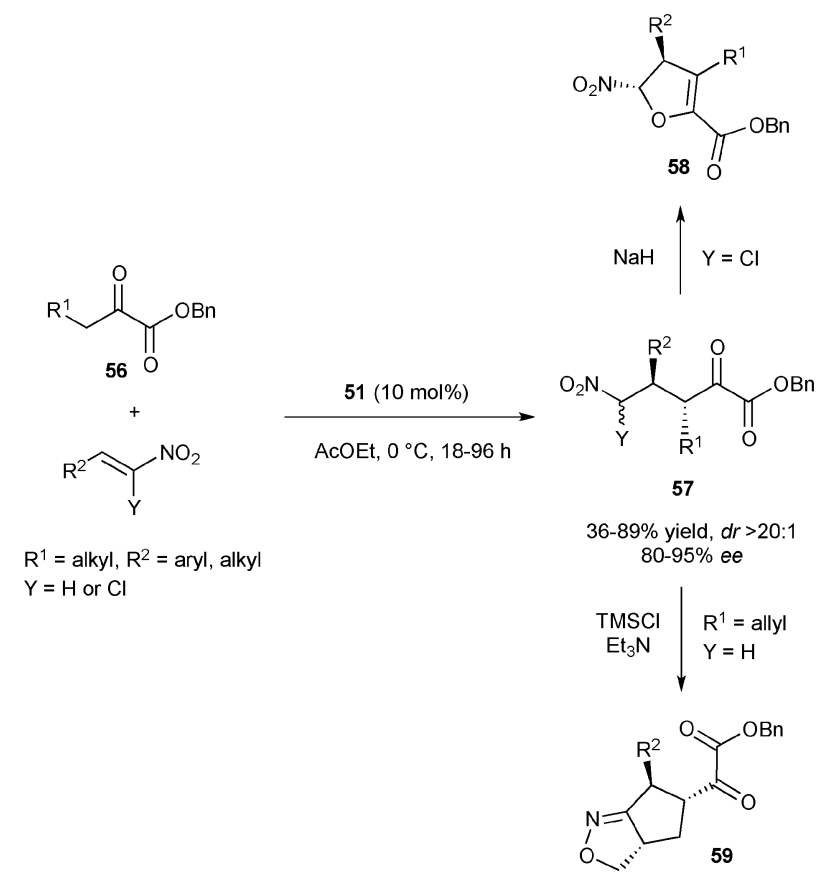

Scheme 20 Enantioselective conjugate addition with 1,2-keto esters.

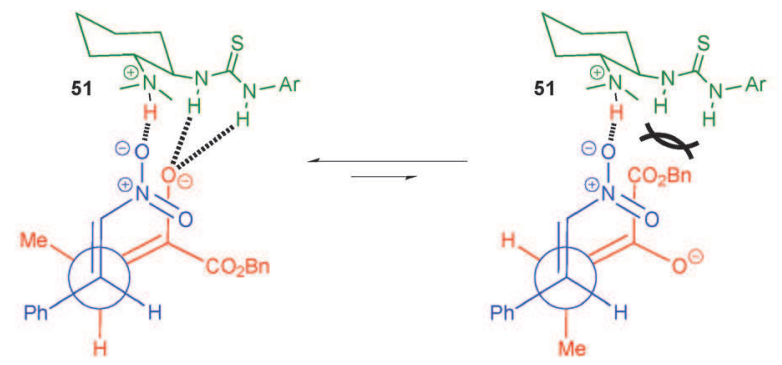

Si of (Z)-enolate attacks $R e$ of $\beta$-nitrostyrene

$\operatorname{Re}$ of (Z)-enolate attacks $R e$ of $\beta$-nitrostyrene<smiles>O=C(OCc1ccccc1)C(=O)[C@@H]([C@H](C[N+](=O)[O-])C(c1ccccc1)c1ccccc1)[N+](=O)[O-]</smiles>

anti
(major)

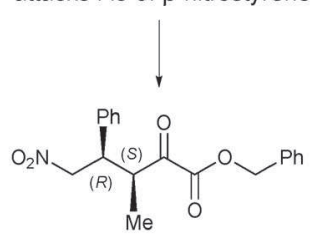

syn

(minor)

Scheme 21 Transition states for the Michael addition of 1,2-keto esters to nitroalkenes.

realised only lately and the first achievement was reported by Rueping et al. in 2008. They judiciously used 2-hydroxy-1,4naphthoquinone $\mathbf{6 0}$ in a domino Michael-acetalisation $\mathrm{C}-\mathrm{O}$ heterocyclisation sequence with $\alpha, \beta$-unsaturated aldehydes 61 under iminium activation with catalyst $\mathbf{6 2}$ leading to synthetically valuable 1,4-pyranonaphthoquinones $\mathbf{6 3}$ in good yields and excellent enantioselectivities (Scheme 22) ${ }^{34}$ Treatment of 63 with sodium borohydride followed by $\mathrm{HCl}$ gave $\beta$-lapachone derivatives 64 in synthetically useful yields. Alternatively, oxidation of 63 produced the lactones $\mathbf{6 5}$ without loss of enantiopurity.

This sequence Michael-acetalisation was later applied by Wang and co-workers with the same 2-hydroxy-1,4-naphthoquinone $\mathbf{6 0}$ 


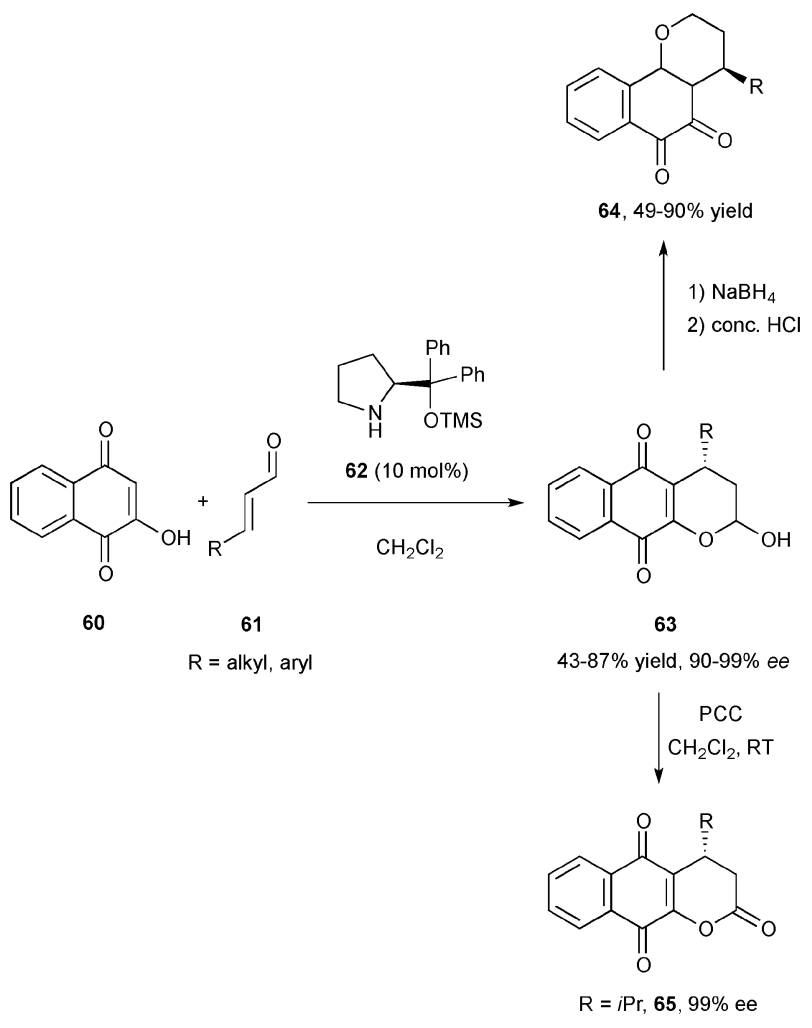

Scheme 22 TMS-diarylprolinol 62-catalysed Michael-acetalisation domino reaction.

but with $\alpha, \beta$-unsaturated pyruvates $\mathbf{6 6}$ as the electrophile under $\mathrm{H}$-bonding catalysis with a chiral 1,2-trans-diaminoindane skeleton based thiourea 67a (Scheme 23). ${ }^{35}$ The enantiomerically
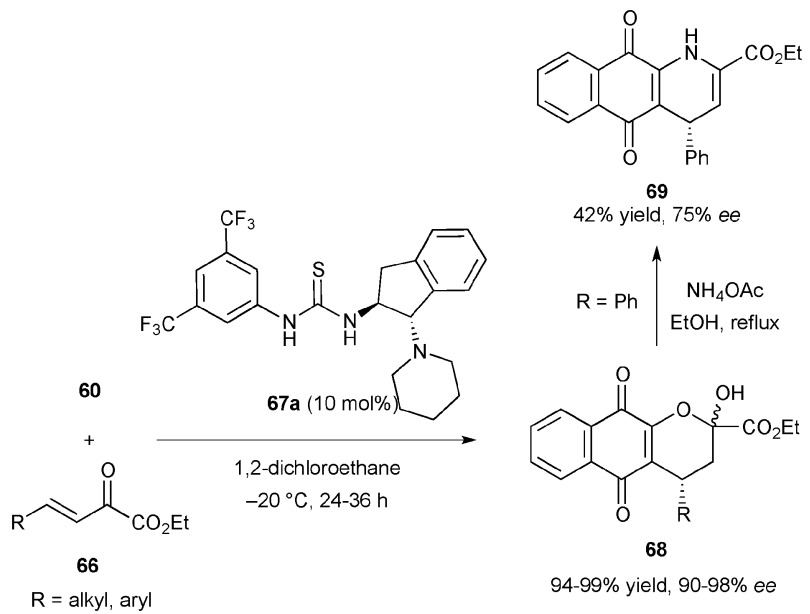

$42 \%$ yield, $75 \%$ ee
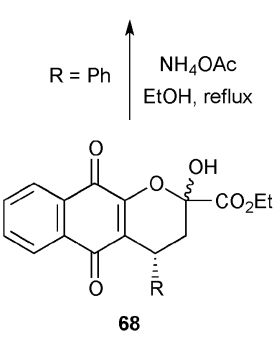

$94-99 \%$ yield, $90-98 \%$ ee

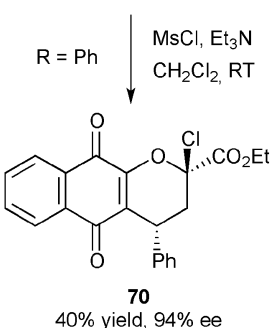

Scheme 23 Enantioselective organocatalysed Michael-acetalisation domino reaction.

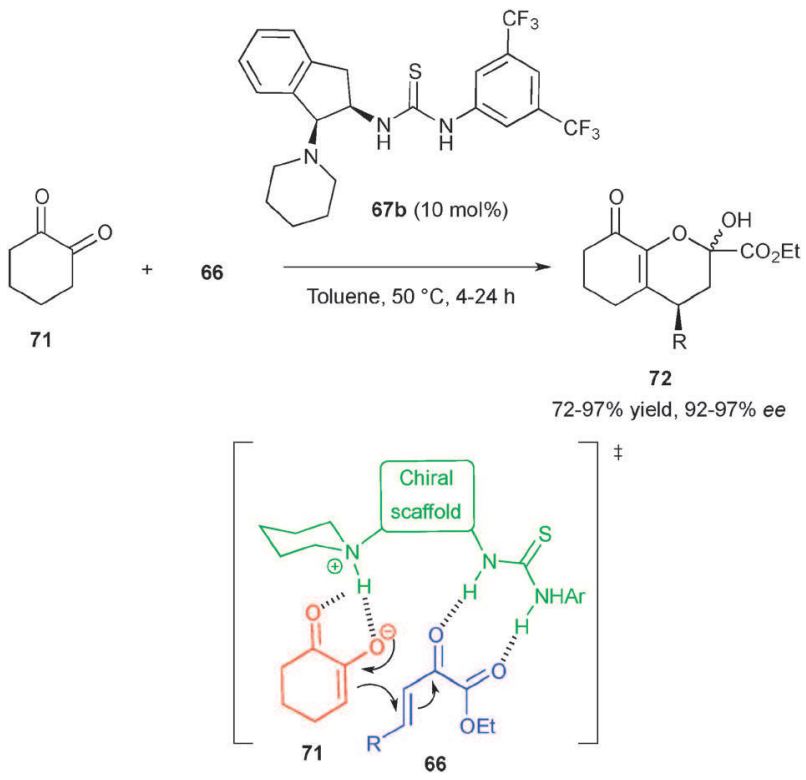

Scheme 24 Enantioselective cascade Michael-enolisation-cyclisation.

enriched naphthoquinones $\mathbf{6 8}$ could be converted to the corresponding dihydropyridine $\mathbf{6 9}$ in moderate yield and a slight erosion in the enantiomeric excess. More interestingly, diastereoselective nucleophilic substitution of the hydroxyl group by a chloride allowed the formation of the quinine derivative $\mathbf{7 0}$ in moderate yield.

Similarly, cyclohexan-1,2-dione (71) was shown by Wang et al. to react as an efficient dual $\mathrm{C}-\mathrm{O}$ nucleophile towards $\alpha, \beta$-unsaturated pyruvates $\mathbf{6 6}$ acting as dual-electrophiles (Scheme 24). ${ }^{36}$ Thus, an enantioselective domino Michaelenolisation-cyclisation sequence catalysed by a chiral 1,2-cisdiaminoindane skeleton based thiourea $\mathbf{6 7 b}$ was developed for the synthesis of valuable dihydro- $2 \mathrm{H}$-pyranes $\mathbf{7 2}$ in high yields and excellent enantioselectivities. The catalyst probably activates diketone 71 and $\beta, \gamma$-unsaturated $\alpha$-keto ester $\mathbf{6 6}$ with its amine and thiourea functional groups enhancing reactivities of both substrates in a chiral environment for the enantiodifferentiating step.

The same concept involving an enantioselective $C$-Michael$O$-cyclisation strategy was reported by Ding and Zhao with arylidenemalononitriles $\mathbf{7 3}$ as electrophiles leading to chiral 2-amino-3-cyano-pyran derivatives $\mathbf{7 5}^{37}$ In this case, the moderate enantioselectivities can be the result of a less effective hydrogen bonding interaction with the nitrile functions and the thiourea moiety of the bifunctional catalyst 74 (Scheme 25).

In complement to these heterocyclisations, 71 acting successively as nucleophile and electrophile was also exploited in an elegant asymmetric organocatalytic domino Michael-aldol carbocyclisation sequence, via enamine-iminium activation with catalyst $\mathbf{6 2} .^{38}$ The optically active polyfunctionalised bicyclo[3.2.1]octanes 77 obtained in good yields from $\alpha, \beta$ unsaturated aldehydes $\mathbf{7 6}$ constitute versatile synthetic platforms upon selective fragmentations. ${ }^{53}$ Oxidative cleavage of the 1,2-diol obtained after sodium borohydride reduction of $\mathbf{7 7}$ afforded the trisubstituted cycloheptanones $\mathbf{7 8}$ with conservation of the optical purity (Scheme 26). Alternatively, bicycle 77 could also be converted to the hemiacetal 79 through 


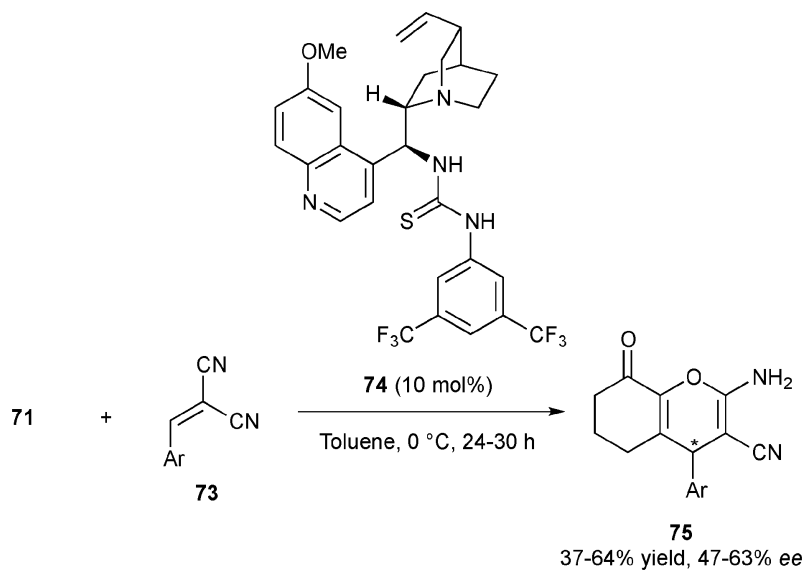

Scheme 25 Enantioselective synthesis of aminopyran derivatives.

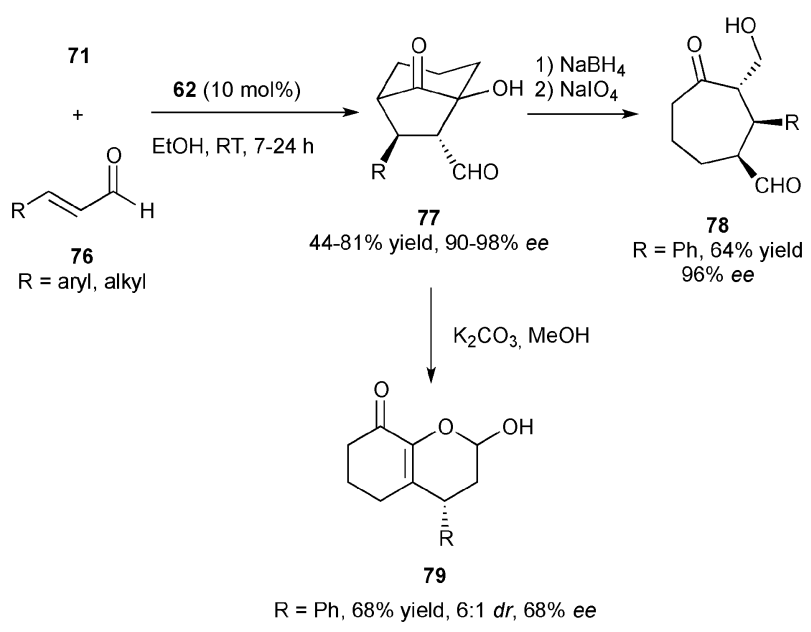

Scheme 26 Enantioselective Michael-aldol domino reaction.

base-induced retro-aldol ring cleavage reaction but with the concomitant destruction of one stereogenic centre.

From a mechanistic point of view, the intermediate iminium 80 evolves through a Michael addition with cyclohexa-1,2dione (71) to generate the transient enamine $\mathbf{8 1}$, which suffers an intramolecular aldol-type reaction affording the bicyclo[3.2.1]octanes 77 after hydrolysis (Scheme 27).

A similar enantioselective domino Michael-Henry cascade involving nitroalkenes $\mathbf{8 2}$ as electrophiles under bifunctional hydrogen-bonding catalysis with $\mathbf{8 3}$ was reported independently shortly after by the same group and Zhao's team (Scheme 28). ${ }^{39}$ Structurally identical bicyclo[3.2.1]octane cores were obtained with lower diastereoselectivity, probably due to a base-catalysed epimerisation at the $\alpha$-nitro position of product 84. Interestingly, when $\alpha$-disubstituted nitroalkenes were employed, bicyclic structures with two adjacent quaternary stereogenic centres were obtained. It is notable that the present methodology involving non-covalent hydrogen-bonding activation necessitates far less catalyst loading ( $1-2 \mathrm{~mol} \%)$ compared to the previous one $(10 \mathrm{~mol} \%)$ that uses the covalent enamineiminium activation.

Recently, simple functionalised acyclic $\alpha$-keto enones $\mathbf{8 5}$ have been employed in an unprecedented organocatalytic asymmetric Nazarov cyclisation affording $\alpha$-hydroxycyclopentenones 87 in

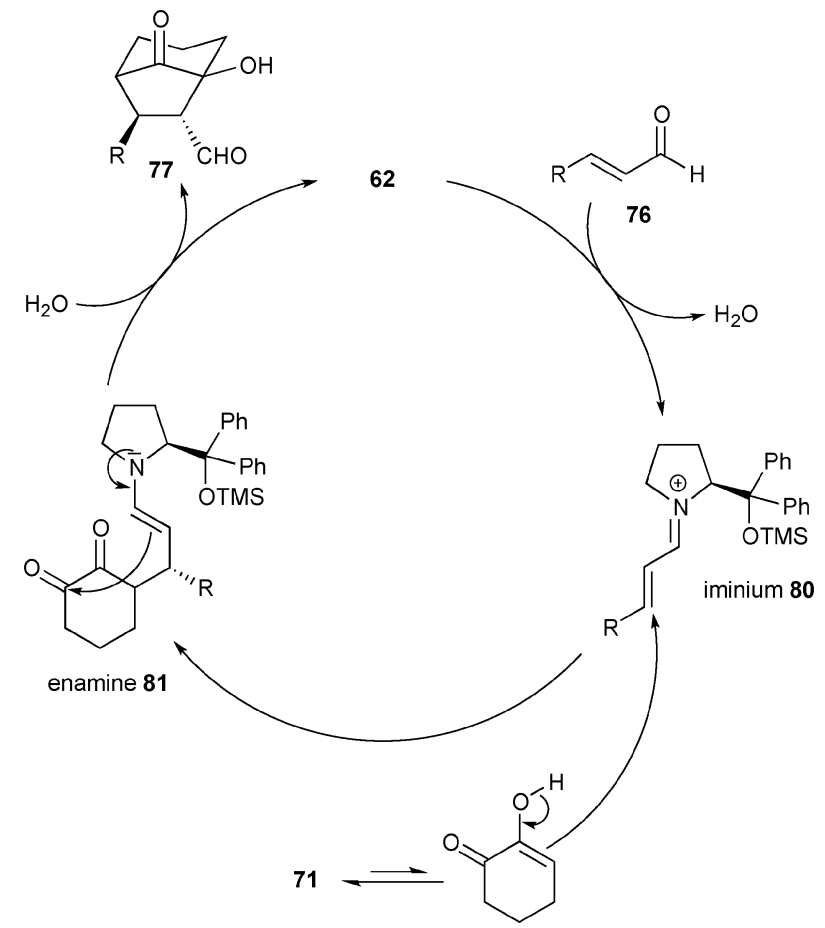

Scheme 27 Mechanism involving iminium-enamine activation for the synthesis of bicyclo[3.2.1]octane systems.

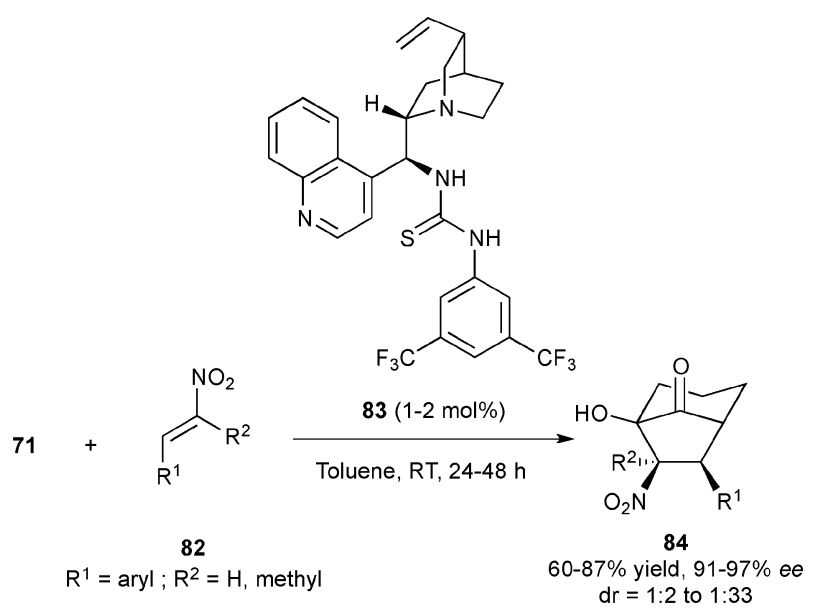

Scheme 28 Enantioselective Michael-Henry domino reaction.

good yields and excellent selectivities (Scheme 29). ${ }^{40}$ The use of bifunctional catalyst $\mathbf{8 6}$ combining Brønsted acidic and Lewis basic moieties allows specific activation of substrates and results in complementary polarisations at the two terminal carbon atoms. The slowness of the reaction is possibly due to product inhibition since $\mathbf{8 7}$ could also bind to the catalyst the same way as that of the starting $\alpha$-keto enones $\mathbf{8 5}$.

Nowadays, the creation of $\mathrm{C}-\mathrm{C}$ bonds by selective activation of 1,2-dicarbonyl pronucleophiles largely leads the way and there are many other interesting reactivities to be discovered. Terada and co-workers opened up this new direction very recently by demonstrating that hydrogen-bonding catalysis could also specifically activate 1,2-keto esters for the creation of $\mathrm{C}-\mathrm{N}$ bonds. They use an axially chiral guanidine base $\mathbf{8 9}$ for the $\alpha$-amination of 1,2-keto esters 15 with $t$-Bu-diazodicarboxylate (88) (Scheme 30). ${ }^{41}$ 


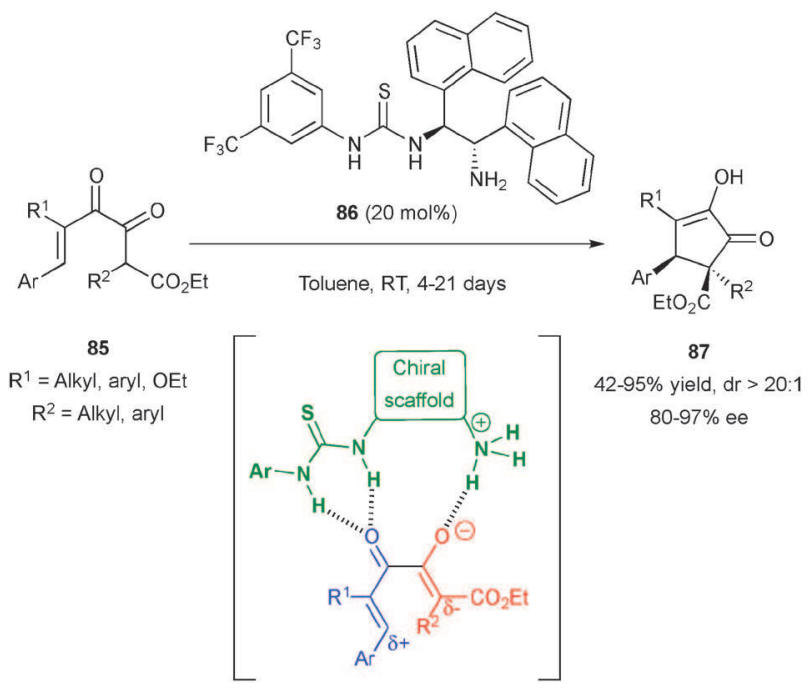

Scheme 29 Organocatalytic asymmetric Nazarov cyclisation.

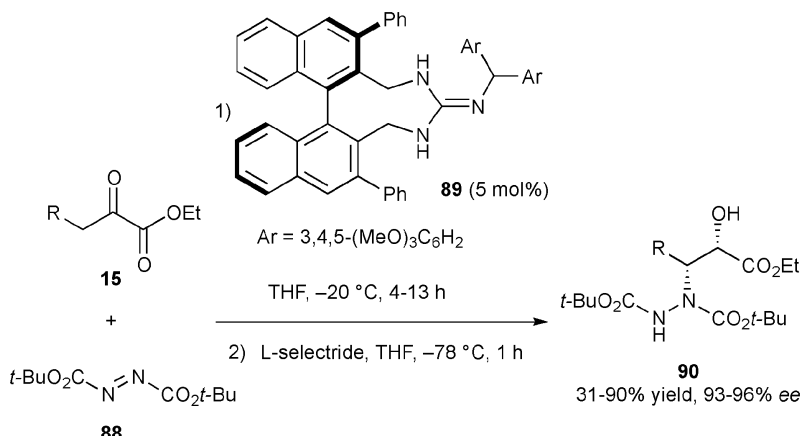

Scheme 30 Organocatalytic enantioselective $\alpha$-amination of 1,2-keto esters with axially chiral guanidine base $\mathbf{8 9}$.

The reaction is quite general and was applied to a wide range of 1,2-keto esters giving, after reduction, the $s y n$ - $\alpha$-hydroxy- $\beta$ hydrazinoesters 90 with always good enantioselectivities and synthetically useful yields.

In order to explain the stereochemistry of the products, the authors proposed the following transition state (Scheme 31). The guanidine moiety of the catalyst $\mathbf{8 9}$ deprotonates the 1,2keto esters $\mathbf{1 5}$ generating the thermodynamically more stable

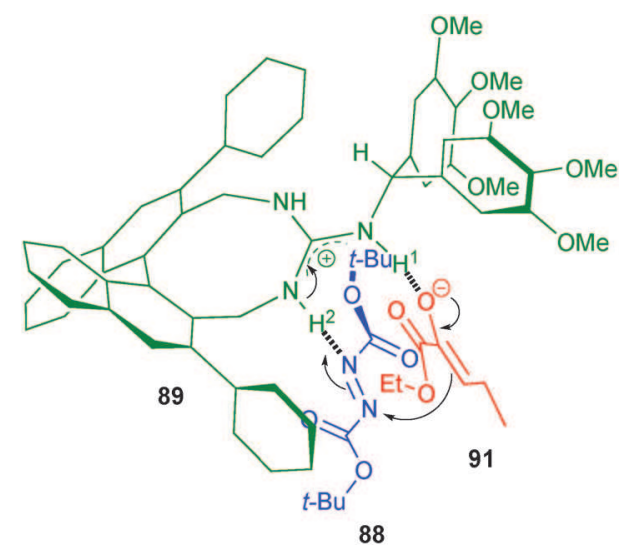

Scheme 31 Transition state for the organocatalysed enantioselective amination of 1,2-keto esters.
(Z)-enolate 91 that could interact with hydrogen $\mathrm{H}^{1}$, which has been found to be more acidic than $\mathrm{H}^{2}$ by electrostatic potential analysis. Meanwhile, the hydrogen $\mathrm{H}^{2}$ would activate the azodicarboxylate $\mathbf{8 8}$ by hydrogen-bonding with its Lewis basic nitrogen. To avoid steric repulsions of both the phenyl ring and the benzhydryl moieties, the $R e$ face of the enolate preferentially attacks the electrophile, which enlighten experimental observations.

The large spectrum of activation modes available with organocatalysts allows, in most of the cases, to be complementary and sometimes to be advantageously competitive with organometallic catalysis offering the undeniable advantage to elaborate more complex and synthetically useful domino transformations.

\section{Stoichiometric transformations}

Non-direct diastereoselective aldolisation of 1,2-keto esters 92 as their (S)-1-amino-2-(1-ethyl-1-methoxypropyl)pyrrolidine (SAEP) hydrazones 94 with aldehydes has been pioneered by Enders and co-workers (Scheme 32 ). ${ }^{42}$ Aldol product 95 could then undergo base-promoted lactonisation to the corresponding hydrazonolactones. Oxidative cleavage of the hydrazone moiety gave the desired isotretronic acids $\mathbf{9 3}$ in good yields and excellent selectivities. This strategy has also been employed for the synthesis of enantiomerically enriched butyrolactones via stereoselective hydrogenation of isotretronic acids 93. ${ }^{43}$ Alternatively, the same group demonstrated that SAEP hydrazones 94 could also be alkylated with various alkyl bromides or iodides for the enantioselective synthesis of 3 -substituted 2-keto esters, ${ }^{44}$ or for an easy access to optically active deoxygenated analogues of ulosonic acids. ${ }^{45}$

More recently, Nazarov cyclisation with $\alpha$-keto enones 96 has been reported with an iminium-enamine activation mode using a stoichiometric amount of chiral 1,2-diamine 97 (Scheme 33). ${ }^{46}$ In the postulated mechanism, the acyclic iminium-enamine ion $\mathbf{9 9}$ is converted to the cyclopentene iminium-enamine ion 100, which are both equally stabilised by a non-bonding electron pair on a nitrogen atom.
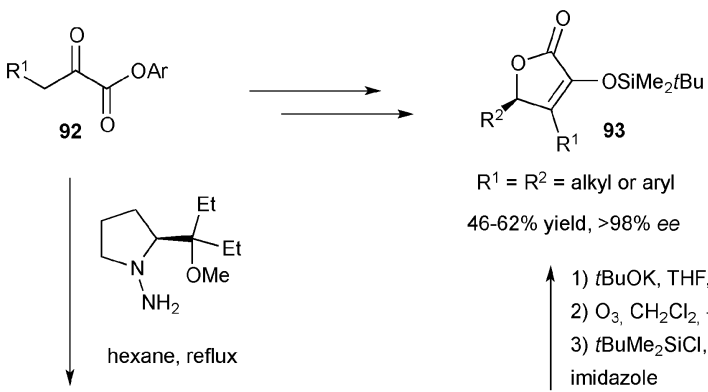

$$
\mathrm{R}^{1}=\mathrm{R}^{2}=\text { alkyl or aryl }
$$

$46-62 \%$ yield, $>98 \%$ ee

$$
\begin{aligned}
& \text { 1) } t \mathrm{BuOK}, \mathrm{THF},-78^{\circ} \mathrm{C} \\
& \text { 2) } \mathrm{O}_{3}, \mathrm{CH}_{2} \mathrm{Cl}_{2,}-78^{\circ} \mathrm{C} \\
& \text { 3) } t \mathrm{BuMe}{ }_{2} \mathrm{SiCl}, \\
& \text { imidazole }
\end{aligned}
$$
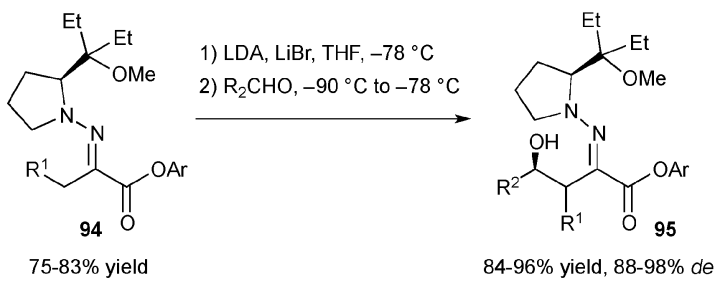

Scheme 32 Enantioselective synthesis of $O$-protected isotetronic acids. 


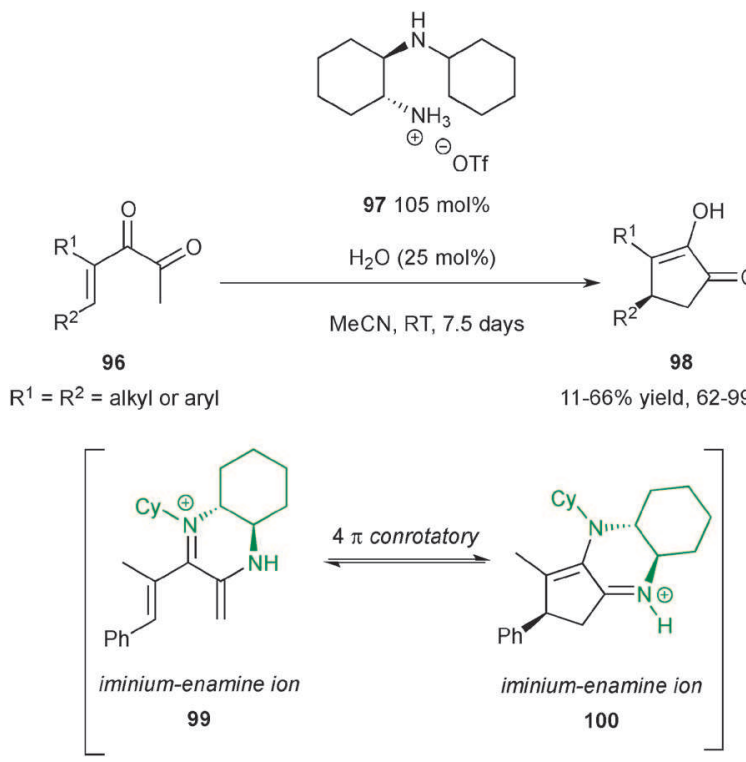

Scheme 33 Enantioselective synthesis of $\alpha$-hydroxycyclopentenones from the Nazarov cyclisation.

Consequently, the equilibrium would be hardly displaced towards 100, arguing for the moderate yields of cyclopentanone derivatives 98 achieved and the very long reaction times.

Although synthetically efficient in some specific cases, the stoichiometric activation of 1,2-dicarbonyls can hardly compete with the extremely powerful development of catalytic methods especially involving organocatalysts.

\section{Miscellaneous}

An other case of 1,2-dicarbonyl compound acting as a nucleophilic component is the following example described by Xiao and coworkers in their asymmetric cyclopropanation reaction between $\beta, \gamma$-unsaturated $\alpha$-keto esters 101 and stabilised sulfur ylides 102 by cooperative hydrogen-bond catalysis using chiral ureas 103 (Scheme 34). In this case, the reactive nucleophilic 1,2-dicarbonyl is the reaction intermediate $\mathbf{1 0 5}$ generated

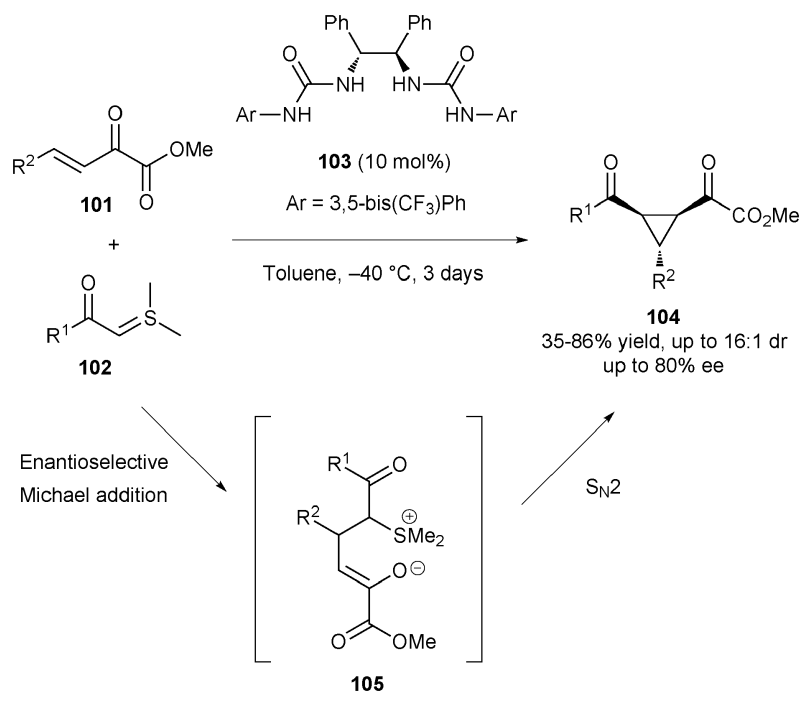

Scheme 34 Asymmetric cyclopropanation reaction.

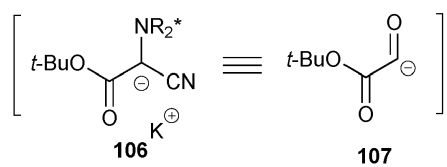<smiles>CN[C@H]1COC(C)(C)O[C@H]1c1ccccc1</smiles><smiles>[R]C(C[N+](=O)[O-])C(=O)C(=O)OCCCC#C</smiles>

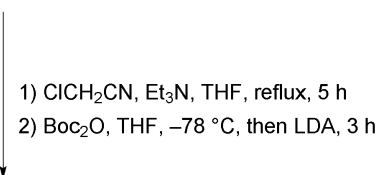

108 $91-98 \%$ ee 2) $\mathrm{Boc}_{2} \mathrm{O}, \mathrm{THF},-78^{\circ} \mathrm{C}$, then $L \mathrm{DA}, 3 \mathrm{~h}$ $\mathrm{AgNO}_{3}, \mathrm{THF} / \mathrm{H}_{2} \mathrm{O}$ RT, 7 days<smiles>CN(C(C#N)C(=O)OC(C)(C)C)[C@@H]1COC(C)(C)O[C@H]1c1ccccc1</smiles>

$73 \%$ yield

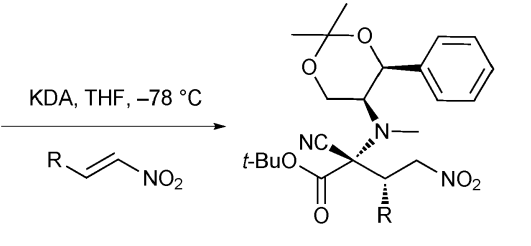

$>98 \%$ yield, $75-96 \%$ de
Scheme 35 Asymmetric nucleophilic glyoxylation of nitroalkenes.

in situ after the 1,4-addition of the sulfur ylide $\mathbf{1 0 2}$ on the Michael acceptor 101. Intermediate 104 then undergo an intramolecular $\mathrm{S}_{\mathrm{N}} 2$ reaction to afford the desired 1,2,3-trisubstituted cyclopropane $\mathbf{1 0 5}$ in moderate to good yield with up to $16: 1$ diastereomeric ratio and $80 \%$ ee.

The next example reported by Enders et al. describes the use of a metalated glyoxylate aminonitrile $\mathbf{1 0 6}$ as a chiral equivalent of a nucleophilic glyoxylate $\mathrm{d}^{1}$ synthon 107 (Scheme 35 ). ${ }^{47,48}$ This umpolung strategy allows the utilisation of pyruvate derivatives as nucleophile components through their acyl anion equivalent providing enantioselective access to $\gamma$-nitro $\alpha$-keto esters $\mathbf{1 0 8}$, precursors of valuable $\gamma$-amino $\alpha$-keto esters.

Rovis and co-workers reported the use of glyoxamides $\mathbf{1 0 9}$ as the glyoxylate donor in a catalytic asymmetric intermolecular Stetter reaction with alkylidenemalonates $\mathbf{1 1 0}$ as the activated alkenes using triazolium salt $\mathbf{1 1 1}$ as the precatalyst (Scheme 36). ${ }^{49}$ This transformation proceeds via the chiral acyl-Breslow intermediate $\mathbf{1 1 2}$ and tolerates many functional

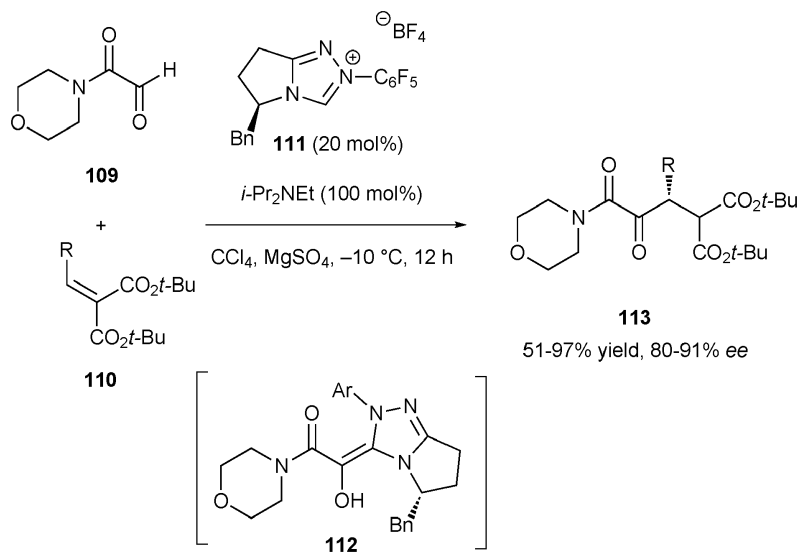

Scheme 36 Asymmetric intermolecular Stetter reaction of glyoxamides with alkylidenemalonates. 

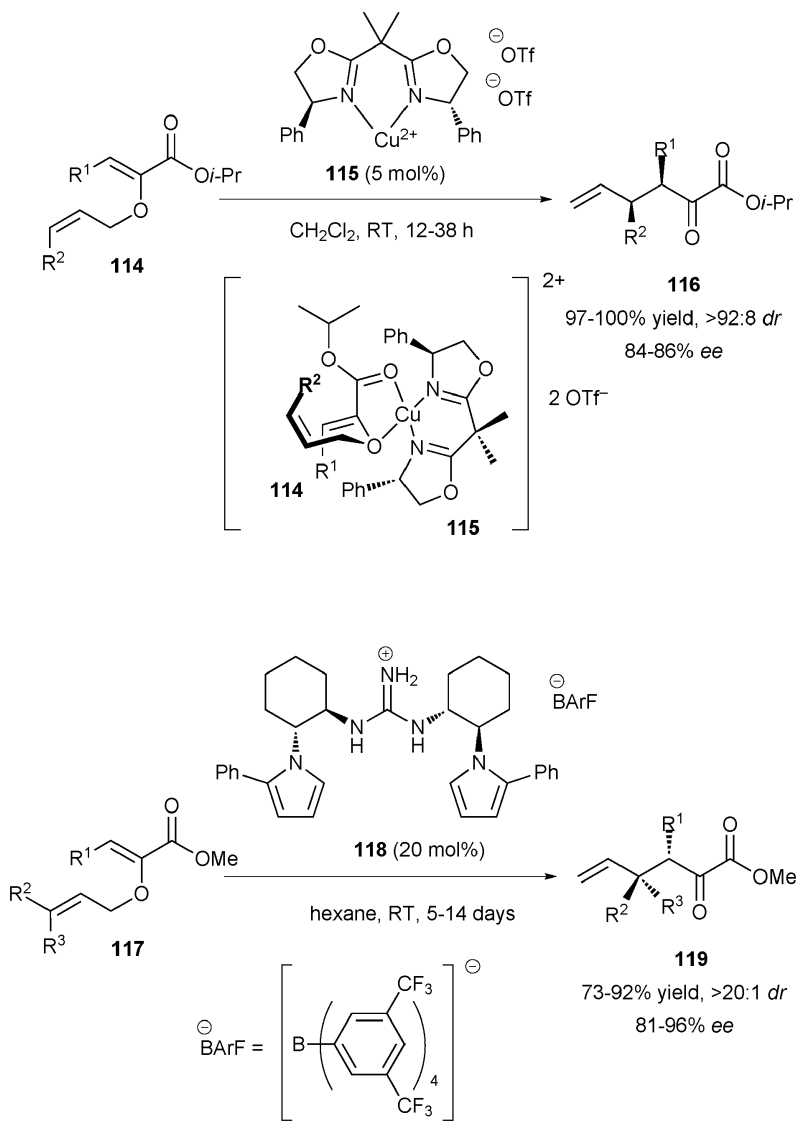

Scheme 37 Catalytic asymmetric Claisen rearrangements.

groups such as benzyl ether, alkyl chloride, thioacetal and alkene for the formation of functionalised 1,2-keto amides $\mathbf{1 1 3 .}$

Finally, the last methodologies allowing the functionalization of 1,2-dicarbonyl compounds at their nucleophilic carbon concerns the enantioselective Claisen rearrangement of 2-alkoxycarbonyl-substituted allyl vinyl ethers 114 and 117 into functionalized 1,2-keto esters 116 and 119, respectively (Scheme 37). This has first been described by Hiersemann et al. using copper(II) bis(oxazoline) complexes 115 as catalysts. ${ }^{50}$ The syn products $\mathbf{1 1 6}$ are obtained in excellent yields and good enantioselectivities. In the transition state, the allyl vinyl ether 114 is probably coordinated to the $\mathrm{Cu}$ (II) in a bidentate fashion with a planar arrangement of the bisoxazoline ligand, the $\mathrm{Cu}(\mathrm{II})$ ion, and the vinyl ether subunit. For a chair-like conformation of the allyl vinyl ether 114, the allyl unit would then approach the vinyl ether double bond on the side opposite to the phenyl group of the Box ligand.

More recently, Uyeda and Jacobsen reported the first organocatalysed enantioselective Claisen rearrangement with the guanidinium salt $\mathbf{1 1 8}$ as an efficient hydrogen-bond donor catalyst. $^{51}$ DFT studies showed a preferred transition state with stabilisation via hydrogen-bonding interactions between catalyst and both the ether- and ester carbonyl-oxygen atoms.

\section{Conclusions}

This article clearly demonstrates that acyclic or cyclic 1,2-dicarbonyls possess very important synthetic potential as pronucleophiles with specific activation modes either with bio-, metal- or organo-catalysts and that some important stoichiometric strategies can be efficient as well. For 1,3dicarbonyl analogues, this potential has been exploited for long time and at a much more important level. ${ }^{52}$ In comparison, 1,2-dicarbonyls were "forgotten" and mostly used as activated ketones for difficult transformations even if a few research groups already uncovered their synthetic utility. At the present time, they proved to be particularly efficient and their ambident reactivity has found important developments in sequential and domino transformations leading to various functionalised optically active targets in the acyclic and cyclic series including three- to seven-membered ring systems by selective formation of $\mathrm{C}-\mathrm{C}, \mathrm{C}-\mathrm{O}, \mathrm{C}-\mathrm{N}$ or $\mathrm{C}-\mathrm{F}$ bonds.

If we put aside Nature's biocatalytic transformations, the use of metal-catalysed methodologies were historically the first to successfully exploit the nucleophilic character of these versatile 1,2-dicarbonyls. The organocatalysis is nowadays able, in most of the cases, to realise the same transformations or to be complementary, with the undeniable advantage to elaborate more complex domino transformations.

Besides some of the spectacular synthetic transformations compiled in this article, we feel that this field of research is still in its infancy and many other ingenious developments should appear shortly. Basically, all reactions known to employ ketones or aldehydes as donors could potentially use these 1,2-dicabonyl compounds with the advantage of possessing additional multiple functionalities that could be further exploited in successive transformations.

\section{Acknowledgements}

W. R. thanks the French Research Ministry for a fellowship award. Financial support from the French Research Ministry, the Universite d'Aix-Marseille and the CNRS are gratefully acknowledged.

\section{Notes and references}

1 G. D. Cody, N. Z. Boctor, T. R. Filley, R. M. Hazen, J. H. Scott, A. Sharma and H. S. Yoder Jr., Science, 2000, 289, 1337.

2 (a) L. Warren and H. Felsenfeld, J. Biol. Chem., 1962, 237, 1421; (b) R. Schauer, Glycobiology, 1991, 1, 449; (c) W. K. Chou, S. Hinderlich, W. Reutter and M. E. Tanner, J. Am. Chem. Soc., 2003, 125, 2455.

3 J. J. Berzelius, Ann. Phys., 1835, 36, 1.

4 (a) J. W. Bode, R. M. Fox and K. D. Baucom, Angew. Chem., Int. Ed., 2006, 45, 1248; (b) J. Ruiz-Rodríguez, J. M. Comstock, J. Z. Dong and J. F. Bode, Chem. Sci., 2011, 2, 1976; (c) I. Pusterla and J. W. Bode, Angew. Chem., Int. Ed., 2012, 51, 513 .

5 D. Seebach, Angew. Chem., Int. Ed. Engl., 1979, 18, 239.

6 Y.-L. Liu, B.-L. Wang, J.-J. Cao, L. Chen, Y.-X. Zhang, C. Wang and J. Zhou, J. Am. Chem. Soc., 2010, 132, 15176.

7 H. G. Wood, C. H. Werkman, A. Hemingway and A. O. Nier, J. Biol. Chem., 1941, 139, 365.

8 (a) M. F. Utter and D. B. Keech, J. Biol. Chem., 1963, 238, 2603; (b) in Biochemistry, ed. D. Voet and J. G. Voet, John Wiley \& Sons, New York, 3rd edn, 2004, p. 615.

9 T. D. Machajewski and C.-H. Wong, Angew. Chem., Int. Ed., 2000, 39, 1352.

10 (a) D. G. Comb and S. J. Roseman, J. Am. Chem. Soc., 1958, 80, 497; (b) D. G. Comb and S. J. Roseman, J. Biol. Chem., 1960, 235, 2529. 
11 (a) H. J. M. Gijsen, L. Qiao, W. Fitz and C.-H. Wong, Chem. Rev., 1996, 96, 443; (b) M. Brovetto, D. Gamenara, P. Saenz Méndez and G. A. Seoane, Chem. Rev., 2011, 111, 4346; (c) P. Clapès, W.-D. Fessner, G. A. Sprenger and A. K. Samland, Curr. Opin. Chem. Biol., 2010, 14, 154.

12 (a) R. L. Halcomb, W. Fitz and C. H. Wong, Tetrahedron: Asymmetry, 1994, 5, 2437; (b) U. Kragl, A. Gödde, C. Wandrey, N. Lubin and C. Augé, J. Chem. Soc., Perkin Trans. 1, 1994, 119; (c) S. Huang, H. Yu and X. Chen, Angew. Chem., Int. Ed., 2007, 46, 2249; (d) H. Yu and X. Chen, Org. Lett., 2006, 8, 2393.

13 B. J. Smith, M. C. Lawrence and J. A. R. G. Barbosa, J. Org. Chem., 1999, 64, 945.

14 (a) C.-H. Lin, T. Sugai, R. L. Halcomb, Y. Ichikawa and C.-H. Wong, J. Am. Chem. Soc., 1992, 114, 10138; (b) W. Fitz, J. R. Schwark and C. H. Wong, J. Org. Chem., 1995, 60, 3663.

15 W. Fitz, J.-R. Schwark and C.-H. Wong, J. Org. Chem., 1993, $\mathbf{5 8}, 264$.

16 M. J. Walters and E. J. Toone, Nat. Protocols, 2007, 2, 1825.

17 (a) K. Juhl, N. Gathergood and K. A. Jørgensen, Chem. Commun., 2000, 2211; (b) N. Gathergood, K. Juhl, T. B. Poulsen, K. Thordrup and K. A. Jørgensen, Org. Biomol. Chem., 2004, 2, 1077.

18 K. Juhl, N. Gathergood and K. A. Jørgensen, Angew. Chem., Int. Ed., 2001, 40, 2995.

19 G. Lu, H. Morimoto, S. Matsunaga and M. Shibasaki, Angew. Chem., Int. Ed., 2008, 47, 6847.

20 Y. Xu, G. Lu, S. Matsunaga and M. Shibasaki, Angew. Chem., Int. Ed., 2009, 48, 3353.

21 A. Nakamura, S. Lectard, D. Hashizume, Y. Hamashima and M. Sodeoka, J. Am. Chem. Soc., 2010, 132, 4036.

22 For racemic version of this reaction, see: H. Maeda and G. A. Kraus, J. Org. Chem., 1997, 62, 2314.

23 D. Shi, Y. Xie, H. Zhou, C. Xia and H. Huang, Angew. Chem., Int. Ed., 2012, 51, 1248.

24 Y. Xu, S. Matsunaga and M. Shibasaki, Org. Lett., 2010, 12, 3246.

25 K. Juhl and K. A. Jørgensen, J. Am. Chem. Soc., 2002, 124, 2420

26 S. Suzuki, Y. Kitamura, S. Lectard, Y. Hamashima and M. Sodeoka, Angew. Chem., Int. Ed., 2012, 51, 4581.

27 For a highlight on organocatalytic activation of 1,2-dicarbonyl compounds, see: W. Raimondi, D. Bonne and J. Rodriguez, Angew. Chem., Int. Ed., 2012, 51, 40.

28 H. Torii, M. Nakadai, K. Ishihara, S. Saito and H. Yamamoto, Angew. Chem., Int. Ed., 2004, 43, 1983.

29 P. Dambruoso, A. Massi and A. Dondoni, Org. Lett., 2005, 7, 4657.

30 J.-M. Vincent, C. Margottin, M. Berlande, D. Cavagnat, T. Buffeteau and Y. Landais, Chem. Commun., 2007, 4782.
31 O. Baslé, W. Raimondi, M. M. Sanchez Duque, D. Bonne, T. Constantieux and J. Rodriguez, Org. Lett., 2010, 12, 5246.

32 W. Raimondi, O. Baslé, D. Bonne, T. Constantieux and J. Rodriguez, Adv. Synth. Catal., 2012, 354, 563.

33 (a) A. Hamza, G. Schubert, T. Soós and I. Pápai, J. Am. Chem. Soc., 2006, 128, 13151; (b) For a recent review of this topic, see: K. Etzenbach-Effers and A. Berkessel, Top. Curr. Chem., 2010, 291, 1 .

34 M. Rueping, E. Sugiono and E. Merino, Angew. Chem., Int. Ed., 2008, 47, 3046.

35 Y. Gao, Q. Ren, S.-M. Ang and J. Wang, Org. Biomol. Chem., 2011, 9, 3691.

36 Q. Ren, Y. Gao and J. Wang, Org. Biomol. Chem., 2011, 9, 5297.

37 D. Ding and C.-G. Zhao, Tetrahedron Lett., 2010, 51, 1322.

38 M. Rueping, A. Kuenkel, F. Tato and J. W. Bats, Angew. Chem., Int. Ed., 2009, 48, 3699.

39 M. Rueping, A. Kuenkel and R. Frölich, Chem.-Eur. J., 2010, 16, 4173; Ding, C.-G. Zhao, Q. Guo and H. Arman, Tetrahedron, 2010, 66, 4423 .

40 A. K. Basak, N. Shimada, W. F. Bow, D. A. Vicic and M. A. Tius, J. Am. Chem. Soc., 2010, 132, 8266.

41 M. Terada, K. Amagai, K. Ando, E. Kwon and H. Ube, Chem.-Eur. J., 2011, 17, 9037. (Corrigendum: Chem.-Eur. J., 2011, 17, 9858).

42 (a) D. Enders, H. Dyker and G. Raabe, Angew. Chem., Int. Ed. Engl., 1993, 32, 421; (b) D. Enders, H. Dyker and F. R. Leusink, Chem.-Eur. J., 1998, 4, 311.

43 D. Enders, H. Sun and F. R. Leusink, Tetrahedron, 1999, 55, 6129.

44 D. Enders, H. Dyker and G. Raabe, Angew. Chem., Int. Ed. Engl., 1992, 31, 618.

45 D. Enders, H. Dyker, G. Raabe and J. Runsink, Synlett, 1992, 901.

46 W. F. Bow, A. K. Basak, A. Jolit, D. A. Vicic and M. A. Tius, Org. Lett., 2010, 12, 8266.

47 D. Enders, M. H. Bonten and G. Raabe, Angew. Chem., Int. Ed., 2007, 46, 2314.

48 For the use of silyl glyoxylates as synthetic equivalent of the glyoxylate anion with aldehydes as electrophiles in the racemic series, see: K. M. Steward and J. S. Johnson, Org. Lett., 2010, 12, 2864.

49 Q. Liu, S. Perreault and T. Rovis, J. Am. Chem. Soc., 2008, 130, 14066.

50 L. Abraham, R. Czerwonka and M. Hiersemann, Angew. Chem., Int. Ed., 2001, 40, 4700.

51 C. Uyeda and E. N. Jacobsen, J. Am. Chem. Soc., 2008, 130, 9228.

52 D. Bonne, Y. Coquerel, T. Constantieux and J. Rodriguez, Tetrahedron: Asymmetry, 2010, 21, 1085.

53 M. Presset, Y. Coquerel and J. Rodriguez, ChemCatChem, 2012, 4, 172. 